NBER WORKING PAPER SERIES

\title{
QUANTITATIVE IMPLICATION OF A DEBT-DEFLATION THEORY OF SUDDEN STOPS AND ASSET PRICES
}

\author{
Enrique G. Mendoza \\ Katherine A. Smith \\ Working Paper 10940 \\ http://www.nber.org/papers/w10940
NATIONAL BUREAU OF ECONOMIC RESEARCH
1050 Massachusetts Avenue
Cambridge, MA 02138
December 2004

We thank Fernando Alvarez, Cristina Arellano, Leonardo Auernheimer, Guillermo Calvo, Daniele CoenPirani, Jonathan Heatcote, Urban Jermann, Fabrizio Perri, Tony Smith, Diego Valderrama, Kirk White and Stan Zin for helpful comments. We also thank seminar participants at the University of Chicago GSB, Georgetown, IDB, Iowa State, Wisconsin, UNC, the 2001 Meeting of the Society for Economic Dynamics and Workshop of the Duke International Economics Group, and the Fall 2003 IFM Program Meeting of the NBER for their suggestions. The views expressed herein are those of the author(s) and do not necessarily reflect the views of the National Bureau of Economic Research.

(C) 2004 by Enrique G. Mendoza and Katherine A. Smith. All rights reserved. Short sections of text, not to exceed two paragraphs, may be quoted without explicit permission provided that full credit, including () notice, is given to the source. 
Quantitative Implication of A Debt-Deflation Theory of Sudden Stops and Asset Prices

Enrique G. Mendoza and Katherine A. Smith

NBER Working Paper No. 10940

December 2004

JEL No. F41, F32, E44, D52

\section{ABSTRACT}

This paper shows that the quantitative predictions of an equilibrium asset pricing model with financial frictions are consistent with the large consumption and current-account reversals and assetprice collapses observed in the "Sudden Stops" of emerging markets crises. Margin requirements set a collateral constraint on foreign borrowing by domestic agents. Foreign traders incur costs in trading assets with domestic agents. Margin constraints bind occasionally depending on equilibrium portfolios and asset prices. When the constraints do not bind, productivity shocks cause standard real-business-cycle effects. When the constraints bind, shocks of the same magnitude cause strikingly different effects that vary with the leverage ratio and the liquidity of asset markets. With high leverage and liquid markets, the shocks trigger margin calls forcing "fire sales" of assets. Fisher's debt-deflation mechanism causes subsequent rounds of margin calls, a fall in asset prices and large consumption and current account reversals. The size of the price decline depends on trading costs parameters because these parameters determine the price elasticity of the foreign traders' asset demand function. Price declines of the magnitude observed in the data require a less-than-unitary price elasticity. Precautionary saving makes Sudden Stops infrequent in the long run so that the model can explain both regular business cycles and the unusually large reversals of consumption and current accounts associated with Sudden Stops.

Enrique G. Mendoza Department of Economics 3105 Tydings Hall University of Maryland College Park, MD 20742 and NBER mendozae@econ.umd.edu
Katherine A. Smith

U.S. Navel Academy

Annapolis, MD

ksmith@usna.edu 


\section{Introduction}

A large fraction of the literature dealing with the emerging markets crises of the last ten years focuses on an intriguing phenomenon referred to as a "Sudden Stop." A Sudden Stop is defined by three stylized facts: sudden, sharp reversals in capital inflows and current account balances, large recessions, and collapses in asset prices and in the relative prices of nontradable goods relative to tradables. Calvo and Reinhart (1999) showed that, while these empirical regularities resemble those typical of the "contractionary devaluations" of the past, the recessions and current account reversals of Sudden Stops have been much larger. Mendoza (2004) showed that the Mexican Sudden Stop of 1995 resulted in a recession, current account reversal, and price collapses that largely exceeded those of a typical cyclical downturn of the Mexican economy.

Table 1 summarizes the key stylized facts of Sudden Stops using quarterly data from the IMF for four well-known cases: Mexico 1994, Argentina 1995, Korea 1997 and Russia 1998. In the Mexican crisis, real equity prices in units of the CPI fell by 29 percent, the current account rose by 5.2 percentage points of GDP, industrial output fell nearly 10 percent and consumption declined by 6.5 percent. Argentina's 1995 "Tequila" crisis resulted in collapses in real equity prices and industrial output similar to Mexico's, a current account reversal of 4 percentage points of GDP, and a decline in consumption of 4 percent. The Korean and Russian crises stood out for their large current account reversals of 11 and 9.5 percentage points of GDP respectively, and for the widespread contagion across world financial markets. Equity prices fell simultaneously across emerging markets in South East Asia in 1997, even in countries where there was no devaluation of the currency, as in Hong Kong where equity prices fell by 20 percent. Sudden Stops also induced higher asset price volatility. The volatility of weekly emerging-market dollar returns doubled from 2 to 4 percent during the 1997 East Asian crisis and the 1998 Russian crisis (see Figure 3.8 in International Monetary Fund (1999)).

The large and sudden current account reversals that occur during a Sudden Stop ultimately reflect a country's loss of access to international capital markets. Hence, there is growing consensus on the view that financial-market frictions are important for explaining Sudden Stops. In line with this view, several theoretical studies have shown how a variety of financial frictions can potentially explain this phenomenon. ${ }^{1}$ In contrast, the quantitative predictions of this class of models are largely unknown. In particular, there is little evidence showing whether the effects of financial frictions are strong enough to account for the observed empirical regularities of Sudden Stops. Moreover, the loss of access to capital markets itself is often modeled as an exogenous shock rather than as an endogenous outcome of financial frictions (see for example Calvo (1998) and Christiano, Gust and Roldos (2002)). Hence, it is yet unknown whether this class of models can produce endogenous

\footnotetext{
${ }^{1}$ See See, for example, Auernheimer and Garcia (2000), Aghion, Baccheta and Banerjee (2000), Caballero and Krishnamurty (1999), Calvo (1998), Calvo and Mendoza (2000a), Cespedes, Chang and Velasco (2001), Choi and Cook (2004), Gopinath (2003), Martin and Rey (2002), and Paasche (2001).
} 
Sudden Stops caused by the standard underlying sources of business cycles in emerging markets, without relying on large, unanticipated shocks that impose the loss of access to capital markets by assumption. This paper attempts to address these issues by studying the quantitative predictions of an equilibrium asset-pricing model with financial frictions in which Sudden Stops are an endogenous response to productivity shocks identical to those that drive a frictionless real-business-cycle model.

The model considers two financial frictions widely used in studies of emerging markets crises (see the survey by Arellano and Mendoza (2003)): (1) collateral constraints, in the form of a margin requirement that limits the ability of agents to leverage foreign debt on domestic asset holdings, and (2) asset trading costs, intended to capture the effects of informational or institutional frictions affecting the ability of foreign traders to trade the equity of emerging economies. Collateral constraints and trading costs interact with the mechanisms at work in RBC models of the small open economy and equilibrium asset pricing models with frictions: uncertainty, risk aversion and incomplete insurance markets.

The transmission mechanism that causes Sudden Stops in the model operates as follows. When the economy's debt is "sufficiently high," an adverse productivity shock of standard magnitude has an effect that it does not have in other states of nature: it triggers margin calls on domestic agents. How high debt needs to be for this to occur is an endogenous outcome of the analysis. If the asset market is liquid, in the sense that the asset holdings of domestic agents are above short-selling limits, margin calls force domestic agents to fire-sell assets to foreign traders. ${ }^{2}$ These traders are slow to adjust their portfolios because of trading costs, and as a result asset prices fall. The price fall triggers new margin calls setting in motion Fisher's debt-deflation mechanism, as domestic agents engage in further fire sales of assets to comply with increasingly tight margin requirements. ${ }^{3}$ At high leverage ratios (i.e., high ratios of debt to the market value of equity), these fire sales cannot prevent a correction in the economy's net foreign asset position, and as a result the price decline is accompanied by reversals in consumption and the current account. Thus, a Sudden Stop takes place.

The analysis of the above financial transmission mechanism as a feature of a dynamic, stochastic general equilibrium asset-pricing model is difficult because equilibrium asset prices are forward-looking objects that represent conditional expected present values of the stream of dividends discounted with stochastic intertemporal marginal rates of substitution. These stochastic discount factors vary depending on whether margin calls take place or not, and this in turn depends on portfolio choices and the current equilibrium price of equity. Thus, equilibrium dynamics feature a nonlinear feedback between equity prices, portofolio choices, stochastic discount factors, and margin

\footnotetext{
${ }^{2}$ This is a "fire sale" in the sense that domestic agents rush to meet margin calls by adjusting their equity position below the position they would optimally hold in the absence of margin calls

${ }^{3}$ Fisher (1933) and Keynes (1932) were the first to propose the idea of debt deflations.
} 
constraints. The paper develops a numerical solution method to explore these nonlinear dynamics using a recursive representation of the model's competitive equilibrium.

The quantitative results show that a baseline scenario calibrated to Mexican data and with minimal trading costs can produce reversals in consumption and the current account similar to those observed in actual Sudden Stops. This occurs even though low trading costs imply a high price elasticity for the foreign traders' asset demand function, and as a result the fall in asset prices is small. Still, this drop in asset prices is much larger than in the absence of financial frictions.

The model's ability to produce larger and more realistic asset price collapses hinges on the size of per-trade asset trading costs. The elasticity of the foreign traders' asset demand function with respect to percent deviations of the fundamentals price from the market price is equal to the inverse of the coefficient that controls the size of these costs. With zero per-trade costs, the foreign trader's demand is infinitely elastic at the fundamentals price, and even in the presence of binding collateral constraints asset prices cannot deviate from their fundamentals level. Sensitivity analysis shows that the model produces Sudden Stops with realistic responses in consumption, the current account and asset prices when per trade costs are set so as to yield a less-than-unitary demand elasticity.

The economy can be inside the high-debt region of the state space in which Sudden Stops occur (i.e., the "Sudden Stop region") because its initial conditions are in that region (for example, if the economy liberalizes its capital account when its foreign debt is high, or if an unanticipated shock increases its debt burden) or because the endogenous long-run stochastic dynamics of the model lead to some of the states inside that region with positive probability. In the latter case, states in the Sudden Stop region are reached as a result of optimal saving and portfolio choices in the face of particular sequences of productivity shocks. Precautionary saving, however, works to minimize the likelihood that these states are reached, since agents dislike large drops in consumption, and hence they wish to save and manage their portfolios so as to avoid frequent Sudden Stops. As a result, longrun business cycle moments for economies with and without financial frictions display minimal differences and the long-run probability of observing binding margin requirements is relatively low, consistent with the fact that Sudden Stops are rare events. In addition, changes in the economic environment that lead to increases in the volatility of asset prices and income, which strengthen incentives for precautionary saving (such as increases in the variability or persistence of productivity shocks) make Sudden Stops larger but reduce their long-run probability.

The transmission mechanism triggering Sudden Stops in this paper differs from others examined in the literature on emerging markets crises based on the closed-economy "financial accelerator" models of Kiyotaki and Moore (1997) and Bernanke, Gertler and Girlchrist (1998). Our model differs in that it introduces elements of equilibrium asset-pricing theory in the presence of aggregate, non-diversifiable risk, "occasionally-binding" collateral constraints and asset trading costs. 
Most models of Sudden Stops with collateral constraints feature borrowing constraints that are always binding at equilibrium or that emerge as an unanticipated, exogenous shock. In contrast, in the model examined here collateral constraints become endogenously binding in states of nature in which the economy's debt is sufficiently high, and agents formulate optimal plans factoring in the possibility of observing these states. Moreover, in contrast with models that adopt the BernankeGertler setup of costly monitoring, in which the external financing premium is unaffected by aggregate risk and is a smooth function of the net worth-debt ratio, the equilibrium dynamics of our model are influenced by non-insurable risk and the risk premium jumps when margin calls occur.

The asset-pricing features of the model are similar to those studied in the closed-economy equilibrium asset pricing literature by Aiyagari (1993), Lucas (1994), Heaton and Lucas (1996), Krusell and Smith (1997) and Aiyagari and Gertler (1999). These authors examined the asset-pricing implications of borrowing constraints, trading costs and short-selling constraints aiming to explain financial facts of U.S. capital markets, particularly the equity premium. The quantitative results of these studies were mixed. Yet, the financial frictions they proposed can still be important for explaining Sudden Stops because empirical regularities like the equity premium relate to moments of the stochastic steady state of a model economy (on which financial frictions were found to produce small effects). In contrast, Sudden Stops are features of equilibrium dynamics when occasionally binding financial frictions bind, even if in the limiting distribution these are rare events.

The rest of the paper proceeds as follows. Section 2 presents the model and discusses the financial transmission mechanism. Section 3 reviews key properties of the model's deterministic competitive equilibrium. Section 4 defines the stochastic competitive equilibrium in recursive form and describes the numerical solution method. Section 5 calibrates the model to Mexican data and studies the model's quantitative predictions. Section 6 concludes.

\section{An Equilibrium Model of Sudden Stops and Debt Deflations}

The model can be summarized as a general equilibrium asset-pricing model with financial frictions and two sets of agents: foreign and domestic. Domestic agents are modeled as a representative-agent small open economy subject to non-diversifiable productivity shocks. The residents of this economy are risk averse and trade bonds and equity with the rest of the world. They face a margin requirement that limits their ability to borrow and a short-selling constraint on their equity holdings. Foreign agents are made of two entities: a set of foreign securities firms specialized in trading equity of the small open economy, and the usual global credit market of non-statecontingent, one-period bonds that determines the world's real interest rate via the standard small-

open-economy assumption. Foreign traders face higher costs than domestic agents in trading the small open economy's equity because of institutional features or informational frictions that are not explicitly modeled (see Frankel and Schmukler (1996) and Calvo and Mendoza (2000b)). 
Margin requirements and trading costs are modeled following Aiyagari and Gertler's (1999) analysis of over-reaction of asset prices. They examined a closed economy in which households face portfolio adjustment costs, securities firms face margin requirements, and income, consumption, and the risk-free real interest rate are exogenous random processes. ${ }^{4}$ In contrast, in the small open economy examined here domestic households face margin requirements, foreign traders are subject to trading costs, and consumption and income are endogenous.

\subsection{Domestic Firms}

There are a large number of identical firms in the small open economy producing a single tradable good using a variable labor input $\left(L_{t}\right)$ and a fixed supply of capital $(K)$. Firms produce this good using a constant-returns-to-scale (CRS) technology $\exp \left(\varepsilon_{t}\right) F\left(K, L_{t}\right)$ where $\varepsilon_{t}$ is a Markov productivity shock. The markets for the final good and labor are competitive, so firms choose labor demand in order to maximize profits:

$$
\exp \left(\varepsilon_{t}\right) F\left(K, L_{t}\right)-w_{t} L_{t}
$$

The assumption that the stock of capital is an exogenous constant is adopted for simplicity. This assumption, together with the assumptions about the structure of preferences introduced below, yields equilibrium sequences of labor, wages and dividends that are independent from those of consumption, portfolio choices and asset prices. The drawback is that, by construction, the model's financial frictions cannot alter the manner in which productivity shocks affect output, factor payments and the labor market. Mendoza (2004) studies a model of Sudden Stops in which a collateral constraint similar to the one introduced in this paper affects capital accumulation via Tobin's Q but in a setup without international equity trading.

Labor demand for $t=0, \ldots, \infty$ is given by the standard marginal productivity condition:

$$
\exp \left(\varepsilon_{t}\right) F_{L}\left(K, L_{t}\right)=w_{t}
$$

Dividend payments for $t=0, \ldots, \infty$ are thus given by:

$$
d_{t}=\exp \left(\varepsilon_{t}\right) F_{K}\left(K, L_{t}\right)
$$

Productivity shocks follow a two-point, symmetric Markov chain. This specification minimizes the size of the exogenous state space $E$ without restricting the variance and first-order autocorrelation of the shocks. The shocks take a high or low value, so $E=\left\{\varepsilon_{H}, \varepsilon_{L}\right\}$. Symmetry implies that $\varepsilon_{L}=-\varepsilon_{H}$, and that the long-run probabilities of each state satisfy $\Pi\left(\varepsilon_{L}\right)=\Pi\left(\varepsilon_{H}\right)=1 / 2$. Transition probabilities follow the simple persistence rule (see Backus, Gregory and Zin (1989)):

$$
\begin{aligned}
& \pi_{\varepsilon_{i} \varepsilon_{j}}=(1-\vartheta) \Pi\left(\varepsilon_{j}\right)+\vartheta \mathrm{I}_{\varepsilon_{i} \varepsilon_{j}}, \\
& \mathrm{I}_{\varepsilon_{i} \varepsilon_{j}}=1 \text { if } i=j \text { and } 0 \text { otherwise, for } i, j=L, H .
\end{aligned}
$$

\footnotetext{
${ }^{4}$ Interestingly, Coen-Pirani (2000) shows that in a closed-economy version of the Aiyagari-Gertler model, in which agents differ in their degree of risk aversion and the risk-free rate is endogenous, margin requirements lower the risk-free rate and increase its volatility but do not alter asset prices
} 
Under these assumptions, the shocks have zero mean, their variance is $\left(\varepsilon_{H}\right)^{2}$, and their autocorrelation coefficient is given by $\vartheta$.

\subsection{Households}

A large number of identical, infinitely-lived households inhabit the small open economy. Their preferences are represented by Esptein's (1983) Stationary Cardinal Utility (SCU) function with an endogenous subjective rate of time preference:

$$
U=E\left[\sum_{t=0}^{\infty} \exp \left\{-\sum_{\tau=0}^{t-1} v\left(c_{\tau}-G\left(L_{\tau}\right)\right\} u\left(c_{t}-G\left(L_{t}\right)\right)\right]\right.
$$

With these preferences, the lifetime marginal utility of date-t consumption includes an "impatience effect," by which a change in $c_{t}$ alters the subjective discount rate applied to the entire future utility stream. The period utility function $u$ is a standard continuously differentiable, concave utility function that satisfies $u(\cdot)<0, u^{\prime}(\cdot)>0, u^{\prime}(0)=\infty$, and $\ln (-u(\cdot))$ convex. The time-preference function $v$ must satisfy $v(\cdot)>0, v^{\prime}(\cdot)>0, v^{\prime \prime}(\cdot)<0$, and $u^{\prime}(\cdot) \exp (v(\cdot))$ nonincreasing. These conditions are easy to satisfy with standard functional forms such as a Constant Relative Risk Aversion (CRRA) period utility function and a logarithmic time-preference function. The argument of the $u$ and $v$ functions is the composite commodity $c-G(L)$ defined by Greenwood, Hercowitz and Huffman (1988), or GHH. $G(L)$ is a concave, continuously differentiable function that measures the disutility of labor. The GHH composite good neutralizes the wealth effect on labor supply by making the marginal rate of substitution between consumption and labor supply depend on the latter only.

Intertemporal preferences with endogenous impatience have a long history in the analysis of small open economies (see, for example, Obstfeld (1982) and Mendoza (1991)). These preferences are important for obtaining a well-defined long-run distribution of foreign assets in stochastic models with incomplete markets. In these models, the standard stationarity assumption of a fixed rate of time preference equal to the world's interest rate implies that foreign assets diverge to infinity, as agents with stochastic incomes try to fully smooth consumption. Preferences with a fixed rate of impatience can support a well-defined stochastic steady state only if the interest rate is set lower than the rate of time preference arbitrarily. In this case, however, the mean foreign asset position is largely determined by the assumed difference between those two rates. Other alternatives address this problem using ad-hoc functions relating the world interest rate to foreign debt or the rate of time preference to average consumption, but these are serious departures from microfoundations and whether they yield similar solutions as preferable alternatives can only be determined case by case. In contrast, Epstein (1983) showed that a Von Neumann-Morgenstern intertemporal utility function satisfies standard preference axioms for choice under uncertainty (generalized to include an axiom requiring preferences over random future consumption to be independent of non-random current consumption) if and only if the utility function is the SCU function. Moreover, the conditions linking 
$u$ and $v$ imply quantitatively small impatience effects (see Mendoza (1991)).

Households maximize SCU subject to the following period budget constraint:

$$
c_{t}=\alpha_{t} K d_{t}+w_{t} L_{t}+q_{t}\left(\alpha_{t}-\alpha_{t+1}\right) K-b_{t+1}+b_{t} R
$$

where $\alpha_{t}$ and $\alpha_{t+1}$ are beginning- and end-of-period shares of the domestic capital stock owned by domestic households, $b_{t}$ and $b_{t+1}$ are holdings of one-period international bonds, $q_{t}$ is the price of equity, and $R$ is the world's gross real interest rate (which is kept constant for simplicity).

In addition to the budget constraint, households face a margin requirement according to which they cannot borrow more than a fraction $\kappa$ of the value of assets offered as collateral: ${ }^{5}$

$$
b_{t+1} \geq-\kappa q_{t} \alpha_{t+1} K, \quad 0 \leq \kappa \leq 1
$$

This is an ex ante collateral constraint that differs in three key respects from ex post collateral constraints (which limit debt not to exceed the discounted one-period-ahead liquidation value of the collateral, as with the Kiyotaki-Moore constraint). First, with a margin clause custody of the collateral is surrendered to the lender at the time the debt contract is entered. Second, margin calls are automatically triggered by declines in the market value of the collateral, giving lenders the option to liquidate the collateral if borrowers fail to meet margin calls. Third, the borrowing limit depends on current equity prices, rather than on expected prices one period ahead. These properties imply that margin constraints are not affected by some of the strategic issues often raised in connection with other collateral constraints, related to whether countries have efficient institutions to enforce the repossession and liquidation of assets in cases of default and to whether this is even optimal for lenders once they reach a default state. It is also worth noting that margin clauses are widely used in international capital markets and take different forms, ranging from explicit margin clauses imposed by lenders or regulatory agencies to implicit margin clauses, like those implied by the investment banks' use of value-at-risk models to set collateral and capital requirements. ${ }^{6}$

Households also face a short-selling constraint $\alpha_{t} \$ \chi$ for $-\infty<\chi<1$ and $t=1, \ldots, \infty$. The case in which $0<\chi<1$ can be interpreted as a portfolio requirement or as a constraint stating that only a fraction of ownership shares on the total physical capital stock of the emerging economy is tradable in international financial markets. The constraint $\alpha_{t} \geq \chi$ is needed to ensure that the state space of portfolio holdings is compact and that the margin requirement is not irrelevant. If unlimited short selling of equity were possible, domestic agents could always undo the effect of the margin constraint.

\footnotetext{
${ }^{5}$ For tractability, domestic agents are not allowed to buy foreign equity and use it as collateral. They do have the choice, however, of buying the foreign risk-free bond and thus reduce their need for collateral.

${ }^{6}$ For example, during the contagion episode after the 1998 Russian default, margin calls were triggered across world capital markets by rising estimates of potential losses produced by value-at-risk models of investment banks that leveraged hedge funds like Long Term Capital Management. As volatility increased and asset prices fell, value-at-risk estimates worsened mandating larger margin calls. Similarly, in the model, a shock that triggers an initial margin call leads to a fall in equity prices that induces even larger margin calls.
} 
The lower bound on equity also serves to support well-behaved equilibria as in other generalequilibrium, incomplete-markets models of asset trading because of the potential for the portfolio $\alpha_{t}+b_{t}$ to become unbounded otherwise.

The first-order conditions of the optimization problem of domestic agents are:

$$
\begin{gathered}
U_{C t}(\cdot)=\lambda_{t} \\
G^{\prime}\left(L_{t}\right)=w_{t} \\
q_{t}\left(\lambda_{t}-\eta_{t} \kappa\right)=E_{t}\left[\lambda_{t+1}\left(d_{t+1}+q_{t+1}\right)\right]+v_{t} \\
\lambda_{t}-\eta_{t}=E_{t}\left[\lambda_{t+1} R\right]
\end{gathered}
$$

$U_{C t}\left(A\right.$ denotes the lifetime marginal utility of date-t consumption, and $\lambda_{t}, \eta_{t}$, and $v_{t}$ are the nonnegative Lagrange multipliers on the budget constraint, the margin constraint, and the shortselling constraint respectively. In addition to conditions (8)-(11), the first-order conditions include the three constraints and the Kuhn-Tucker conditions associated with each constraint.

The above first-order conditions have straightforward interpretation, with the caveat of the impatience effect on marginal utility. The optimal labor supply condition in (9) shows the effect of the GHH composite good: the marginal disutility of labor is set equal to the real wage without intertemporal effects. Given the realization of $\boldsymbol{\varepsilon}_{t}$, this condition and the labor demand condition (9) determine equilibrium labor and wages, and hence output and dividends, separately from the rest of the model. Conditions (10) and (11) are Euler equations for equity and foreign bonds. Given the definition of the return on equity, $R_{t+1}^{q} /\left(d_{t+1}+q_{t+1}\right) / q_{t}$, these conditions can be combined to derive the following expression for the expected premium on domestic equity:

$$
E_{t}\left[R_{t+1}^{q}\right]-R=\frac{\eta_{t}(1-\kappa)-\frac{v_{t}}{q_{t}}-C O V_{t}\left(\lambda_{t+1}, R_{t+1}^{q}\right)}{E_{t}\left[\lambda_{t+1}\right]}
$$

If margin and short-selling constraints never bind (i.e., $\eta_{t}=v_{t}=0$ for all $t$ ), this expression yields the standard result for the equity premium of a frictionless asset-pricing model. In contrast, a binding margin requirement at date $t$ (i.e., $\eta_{t}>0$ ) increases the equity premium because of the pressure that margin calls exert on households to fire-sell equity, depressing the current equity price. This direct effect of the margin constraint is limited to the fraction $(1-\kappa)$ of the shadow value $\eta_{t}$ because, when the margin constraint binds, the marginal benefit of equity holdings increases by the fraction $\kappa$, since more equity holdings help households to relax the borrowing constraint. A binding short-selling constraint (i.e., $v_{t}>0$ ) increases the marginal gain of additional equity holdings and has no effect on the marginal benefit of saving in assets, hence it reduces the equity premium.

In addition to the direct effect, binding margin constraints have an indirect effect. This effect follows from the fact that the conditional covariance between $\lambda_{t+1}$ and $R_{t+1}^{q}$ in the right-hand-side of 
(12) is likely to be more negative when margin calls are possible than with a perfect credit market. ${ }^{7}$ This occurs in turn because the risk of a binding borrowing limit at $t+1$ hampers the ability of households to smooth consumption, leading to precautionary saving, increased consumption volatility and a lower covariance between consumption and equity returns (i.e., $\lambda_{t+1}$ rises while $R_{t+1}^{q}$ falls). The intuition is that equity is a bad hedge against the risk of margin calls because the more negative the covariance between these two variables, the more likely it is that margin calls coincide with low expost equity returns. Households will thus demand a larger equity premium to reflect this unhedged risk. Note also that, as in Aiyagari and Gertler (1999), equation (12) predicts that excess returns may exist whenever it is possible for a margin call to occur in the future, even if the margin requirement is not binding at present.

To analyze further the effects of margin calls on equity prices, consider the following forward solution derived from equations (10) and (11):

$$
q_{t}=E_{t}\left(\sum_{i=0}^{\infty}\left[\prod_{j=0}^{i}\left(\frac{\lambda_{t+j}}{E_{t+j}\left[\lambda_{t+1+j} R\right]+\eta_{t+j}(1-\kappa)}\right)\right] M_{t+1+i} d_{t+1+i}\right)
$$

where $M_{t+1+i} / \lambda_{t+1+i} / \lambda_{t}$ for $i=0, \ldots, 4$, is the stochastic intertemporal marginal rate of substitution between $c_{t+1+i}$ and $c_{t}$. If the margin requirement never binds, this expression collapses again to a standard asset-pricing formula. If margin calls are possible at any date, the rates at which domestic agents discount future dividends in their valuation of asset prices are altered by the direct and indirect effects of margin constraints. The net effect on the price of equity is easier to interpret by solving forward the expression $E_{t}\left[R_{t+1}^{q}\right]=E_{t}\left[\left(d_{t+1}+q_{t+1}\right) / q_{t}\right]$ to obtain:

$$
q_{t}=E_{t}\left(\sum_{i=0}^{\infty}\left[\prod_{j=0}^{i}\left(E_{t}\left[R_{t+1+j}^{q}\right]\right)^{-1}\right] d_{t+1+i}\right)
$$

where the sequence of $E_{t}\left[R_{t+1+j}^{q}\right]$ is given by (12). Hence, if the direct and indirect effects of margin calls lead to excess equity returns, a margin requirement that binds at present or is expected to bind in the future implies that some of the expected returns used to discount the future stream of dividends increase, and thus the current price of equity bid by households falls.

It is important to note that at equilibrium the direct and indirect effects of margin calls are amplified by the Fisherian debt-deflation process that results from the interaction between domestic agents and foreign traders in the equity market. A productivity shock triggers an initial margin call. Domestic agents then try to liquidate equity to meet the call, which puts downward pressure on the equilibrium equity price because domestic agents trade with foreign traders who incur trading costs and are thus slow to adjust their portfolios. The resulting fall in equity prices tightens the margin

\footnotetext{
${ }^{7}$ This is the Heaton-Lucas indirect effect of trading costs on asset prices, which occurs "to the extent that the increase in consumption volatility increases the covariance between individual consumption and the net return on stock" (Heaton and Lucas (1996), p. 465)
} 
constraint, which leads to further equity sales and further tightening of the margin constraint.

\subsection{Foreign Securities Firms}

Foreign securities firms specialize in holding equity of the small open economy. These firms maximize the present discounted value of dividends paid to their global shareholders, facing trading costs that are quadratic in the volume of trades (as in Aiyagari and Gertler (1999)) and in a fixed recurrent cost. ${ }^{8}$ These trading costs represent the disadvantaged position from which foreign traders operate relative to domestic agents when trading domestic equity. This disadvantage may result from informational frictions (i.e., domestic residents may be better informed on economic and political variables relevant for determining the earnings prospects of local firms), ${ }^{9}$ or because of countryspecific institutional features or government policies that favor domestic residents. The recurrent cost represents fixed costs for participating in an emerging equity market that foreign traders incur just to be ready to trade, even if they do not actually trade in any given period.

Foreign traders choose $\alpha_{t+1}^{*}$ for $t=0, \ldots, 4$ so as to maximize the value of foreign securities firms per unit of capital:

$$
D / K=E_{0}\left[\sum_{t=0}^{\infty} M_{t}^{*}\left(\alpha_{t}^{*}\left(d_{t}+q_{t}\right)-q_{t} \alpha_{t+1}^{*}-q_{t}\left(\frac{a}{2}\right)\left(\alpha_{t+1}^{*}-\alpha_{t}^{*}+\theta\right)^{2}\right)\right], \quad \theta, a \geq 0
$$

where $M_{0}^{*} / 1$ and $M_{t}^{*}$ for $t=1, \ldots, 4$ are the exogenous marginal rates of substitution between date- $t$ consumption and date- 0 consumption for the world's representative consumer. For simplicity, these marginal rates of substitution are set to match the world real interest rate, so $M_{t}^{*} / R^{t}$. Trading costs are given by $q_{t}(a / 2)\left(\alpha_{t+1^{-}}^{*} \alpha_{t}{ }_{t}+\theta\right)^{2}$. The recurrent entry cost is $\theta$ and $a$ is an adjustment cost coefficient that determines the price elasticity of the foreign trader's demand for equity, as shown below. Note that $\theta$ induces an asymmetry in the manner in which trading costs operate. With $\theta=0$, the total cost of increasing or reducing equity holdings by a given amount is the same, but with $\theta>0$ the total cost of reducing equity holdings is higher.

At an interior solution, the first-order conditions for the above optimization problem imply that the foreign traders' demand for equity follows the following partial adjustment rule:

$$
\left(\alpha_{t+1}^{*}-\alpha_{t}^{*}\right)=\frac{1}{a}\left(\frac{q_{t}^{f}}{q_{t}}-1\right)-\theta
$$

\footnotetext{
${ }^{8}$ Trading costs are often modeled as quadratic in the value of trades (see Heaton and Lucas (1996)). The Aiyagari-Gertler specification, in which the equity price enters in linear form, yields a more tractable recursive specification of the trader's optimality conditions.

${ }^{9}$ Foreign traders may be less informed because they cannot access or process country-specific information as easily as domestic agents or because they optimally choose not to do so. Calvo and Mendoza (2000b) provide two arguments for why the latter can occur. First, with limited short-selling, a foreign investor's gain from paying information costs falls as the number of emerging markets in which to invest grows. Second, if portfolio manager's face performance incentives with marginal costs larger than rewards, there is a range of multiple optimal portfolios in which managers mimic each other's behavior.
} 
where $q_{t}^{f}$ is defined as the "fundamentals" price:

$$
q_{t}^{f} \equiv E_{t}\left(\sum_{i=0}^{\infty} M_{t+1+i}^{*} d_{t+1+i}\right)
$$

Note that this price is not equivalent to the asset price that would prevail in the absence of collateral constraints, because even then equilibrium equity prices would reflect the premium that risk-averse domestic agents would demand for holding equity (whereas the fundamentals price as defined in (17) implies zero equity premia since $\left.M_{t}^{*} / R^{t}\right)$.

According to (16), foreign traders increase their demand for equity by a factor $1 / a$ of the percent deviation of the date-t fundamentals price above the actual price (i.e., $1 / a$ is the elasticity of their demand for equity with respect to the percent deviation of $q_{t}^{f}$ relative to $q_{t}$ ). If there were no per-trade trading costs, their demand for equity would be infinitely elastic at $q_{t}^{f}$ and domestic agents could liquidate the shares needed to meet margin calls at an infinitesimal discount below $q_{t}^{f}$.

An important implication of the incompleteness of asset markets in the model is that, despite asset trading between foreign and domestic agents, the stochastic sequences of their discount factors, $M_{t+1+i}{ }^{*}$ and $M_{t+1+i}$ for $i=0, . ., \infty$, are not equalized. With complete markets or under perfect foresight, both sequences are equalized at the reciprocal of the world's interest rate (compounded $i$ periods). Under uncertainty and incomplete markets, however, this is not the case even with an exogenous, risk-free world interest rate. The domestic stochastic discount factors are endogenous and reflect the direct, indirect, and debt-deflation effects of margin calls.

\subsection{Competitive Equilibrium}

Given the Markov process of productivity shocks and the initial conditions $\left(b_{0}, \alpha_{0}, \alpha_{0}{ }^{*}\right)$, a competitive equilibrium is defined by stochastic sequences of allocations $\left[c_{t}, L_{t}, b_{t+1}, \alpha_{t+1}, \alpha_{t+1}^{*}\right]_{t=0}{ }^{\infty}$ and prices $\left[w_{t}, d_{t}, q_{t}, R_{t}^{q}\right]_{t=0}^{\infty}$ such that: (a) domestic firms maximize dividends subject to the CRS technology, taking factor and goods prices as given, (b) households maximize SCU subject to the budget constraint, the margin constraint, and the short-selling constraint, taking as given factor prices, goods prices, the world interest rate and asset prices, (c) foreign securities firms maximize the expected present value of dividends net of trading costs, taking as given asset prices, and (d) the market-clearing conditions for equity, labor, and goods markets hold.

\section{Perfect Foresight Implications}

Under perfect foresight, conditions (12) and (13) reduce to the following:

$$
\begin{gathered}
R_{t+1}^{q}-R=\frac{\eta_{t}(1-\kappa)}{\lambda_{t+1}} \\
q_{t}=\sum_{i=0}^{\infty}\left(\prod_{j=0}^{i}\left[1+(1-\kappa) \frac{\eta_{t+j}}{\lambda_{t+j}-\eta_{t+j}}\right]^{-1} R^{-i} d_{t+1+i}\right)
\end{gathered}
$$

As these expressions show, under perfect foresight there is a premium on domestic equity only if the 
margin requirement binds at date $t$, and this premium reflects only the direct effect of margin calls.

\subsection{Comparing the Margin Constraint with the Kiyotaki-Moore Constraint}

The above perfect-foresight results can be used to compare the asset-pricing implications of the margin constraint with those of the collateral constraint examined by Kiyotaki and Moore (1997), or KM. The KM constraint requires $R b_{t+1} \geq-q_{t+1} \alpha_{t+1} K$. This constraint yields the following asset pricing condition (using $\eta$ now for the multiplier on the KM constraint):

$$
q_{t}=\sum_{i=0}^{\infty}\left[1-\frac{\eta_{t+i}}{\lambda_{t+i}}\right]^{-1} R^{-i} d_{t+1+i} .
$$

Thus, the KM constraint is similar to the margin constraint in that (a) if the constraint binds the equity price is lower than the fundamentals price because of the higher effective discount rate that households face with a binding borrowing constraint, ${ }^{10}$ and (b) if the constraint binds in the future, the current equity price is lower than the fundamentals price. The differences in the product terms of (19) and (20) indicate, however, that the quantitative implications of the two constraints differ. In turn, those product terms differ because a margin requirement binding at $t$ alters the discount rates domestic agents apply to both dividends and capital gains at $t+1$, while a binding KM constraint alters only the discount rate applied to dividends.

\subsection{Deterministic Stationary Equilibria}

We examine next the implications of margin requirements and trading costs for the deterministic steady state. At steady state, the fundamentals price is $\bar{q}^{f}=\bar{d} /(R-1)$. The foreign traders' demand function implies then that asset prices and the return on equity must satisfy:

$$
\begin{gathered}
\bar{q}=\frac{\bar{q}^{f}}{(1+a \theta)} \leq \bar{q}^{f} \\
\bar{R}^{q}=1+\frac{\bar{d}}{\bar{q}} \geq 1+\frac{\bar{d}}{\bar{q}^{f}}=R
\end{gathered}
$$

These steady-conditions include two scenarios: a frictionless steady state, with zero trading costs and non-binding margin constraints, and a steady state with financial frictions.

Consider first the frictionless steady state. The above steady-state conditions state that in the long run the equity price will equal the fundamentals price, and the equity premium will vanish, only if per-trade or recurrent trading costs are zero. However, this is necessary but not sufficient to support this outcome as a stationary equilibrium because the domestic agents' asset pricing condition will only hold at $\bar{q}=\bar{q}^{f}$ if it is also true that the margin constraint does not bind (see equation (19)).

In this frictionless steady state, there is a unique level of steady-state consumption independent of initial conditions. Since the margin constraint does not bind (i.e., $\bar{\eta} / \bar{\lambda}=0$ ), the Euler equations imply that steady-state consumption is given by the condition $\exp (v(\bar{c})-G(\bar{L}))=R$. The stock

\footnotetext{
${ }^{10}$ Note that the Euler equation for bonds (eq. (11)) implies that $0 \leq 1-\eta_{t} / \lambda_{t} \leq 1$.
} 
of savings, $\bar{S} \equiv \bar{b}+\bar{q} \bar{\alpha} K$, also has a unique steady state because savings and consumption are related by the budget constraint $\bar{c}=\bar{w} \bar{L}+\bar{S}(R-1)$. The steady-state portfolio, however, is undetermined. Any portfolio with $\chi \leq \bar{\alpha} \leq \bar{S} /\left((1-\kappa) \bar{q}^{f}\right)$ and $\bar{b}=\bar{S}-\bar{q} \bar{\alpha} K$ supports the unique level of steady-state savings. The steady-state equilibrium cannot be supported with either smaller equity holdings, because the short-selling constraint would not hold, or larger equity holdings, because this would imply a level of debt that would make the margin constraint bind.

The situation is very different in a steady state in which financial frictions matter. Supporting this steady-state equilibrium requires: (a) positive per trade and recurrent trading costs and (b) a binding margin constraint. By condition (21), positive per trade and recurrent trading costs imply a steady-state equity price below the fundamentals price and a long-run equity premium equal to $\theta a(R-1)$. Since the Euler equations imply that steady-state consumption satisfies $\exp (v(\bar{c})-G(\bar{L}))=R /(1-\bar{\eta} / \bar{\lambda})$, it follows that the margin constraint must bind (otherwise $\bar{c}$ and $\bar{q}$ would be the same as in the frictionless equilibrium, which is a contradiction). The implicit solution for steady-state consumption can also be written as $\exp (v(\bar{c})-G(\bar{L}))=R+(R-1)[(a \theta) /(1-\kappa)]$. Hence, the "effective" gross real interest rate that agents face in the steady state with frictions exceeds the gross world interest rate by the factor $[(a \theta) /(1-\kappa)]$ of the net world interest rate. Higher trading costs (higher $a \theta$ ) or tighter margin requirements (lower $\kappa$ ) are akin to an increase in the real interest rate in terms of their effect on steady-state consumption.

The model can support stationary equilibria at the higher effective interest rate of the scenario with frictions because it allows the endogenous rate of time preference to increase accordingly. Thus, a standard formulation of preferences with a constant rate of time preference would not be able to support these long-run equilibria with financial frictions.

In contrast with the frictionless case, the steady-state portfolio is now uniquely determined and is independent of initial conditions. The unique portfolio is given by $\bar{\alpha}=\bar{S} /((1-\kappa) \bar{q})$ and $\bar{b}=-\kappa \bar{q} \bar{\alpha} K$. Domestic agents hold more equity than in the frictionless case because the margin constraint increases long-run savings and because the trading costs make the equity price fall.

These results suggest that trading costs and credit constraints that bind at steady state can produce a long-run "home bias" in portfolio holdings and long-run excess returns on emerging markets. For a given coefficient $\kappa$, recurrent trading costs and binding margin constraints increase home bias and excess returns by increasing savings and lowering equity prices. These savings and price effects are stronger the higher are $\theta$ or $a$ because higher values of these parameters imply a lower long-run equity price, a larger premium on domestic equity, and higher steady-state savings.

\section{Recursive Equilibrium and Numerical Solution Method}

The model's competitive equilibrium is solved by reformulating it in recursive form and applying a numerical solution method. The algorithm is designed to deal with four key features of the 
model: incomplete markets of contingent claims, portfolio choice in a two-agent equilibrium setting, forward-looking asset prices, and occasionally binding margin constraints.

To represent the equilibrium in recursive form, define $\alpha$ and $b$ as the endogenous state variables and $\varepsilon$ as the exogenous state. Since wages, dividends and factor payments depend only on $\varepsilon$, they are represented by the functions $w(\varepsilon), d(\varepsilon)$ and $L(\varepsilon)$ that solve jointly equations (2), (3) and (9). The state space of equity positions spans the interval $\left[\chi, \alpha^{\max }\right]$ with NA discrete nodes and the state space of bond positions spans the interval $\left[b^{\min }, b^{\max }\right]$ with NB discrete nodes. The state space of endogenous states is thus given by the set $Z=\left[\chi, \alpha^{\max }\right] \times\left[b^{\min }, b^{\max }\right]$ of $\mathrm{NA} \times \mathrm{NB}$ elements.

The recursive asset pricing function is defined as $q(\alpha, b, \varepsilon): E \times Z \rightarrow R^{+}$. For any state $(\alpha, b, \varepsilon) \in E \times Z$, this pricing function must satisfy the condition that $q(\alpha, b, \varepsilon) \in\left[q^{\min }(\alpha, \varepsilon), q^{\max }(\alpha, \varepsilon)\right]$, where $q^{\min }(\alpha, \varepsilon)=q^{f}(\varepsilon) /[1+a(\alpha-\chi+\theta)]$ and $q^{\max }(\alpha, \varepsilon)=q^{f}(\varepsilon) /\left[1+a\left(\alpha-\alpha^{\max }+\theta\right)\right]$ are maximum and minimum prices along the foreign traders' demand curve. These bounds of the pricing function follow from the fact that when domestic equity holdings hit either $\chi$ or $\alpha^{\max }$, the foreign traders' price prevails because they are at the "short side" of the market.

Imposing market clearing in the equity market and inverting the foreign trader's demand function to use it as pricing function, the optimal plans of the domestic economy can be represented by the following dynamic programming problem:

$$
\begin{aligned}
& V(\alpha, b, \varepsilon)=\max _{\left(\alpha^{\prime}, b^{\prime}\right) \in Z, c}\left\{\frac{\left[c-\frac{L(\varepsilon)^{\delta}}{\delta}\right]^{1-\sigma}-1}{1-\sigma}+\exp \left(-\beta\left[L n\left(1+c-\frac{L(\varepsilon)^{\delta}}{\delta}\right)\right]\right) E\left[V\left(\alpha^{\prime}, b^{\prime}, \varepsilon^{\prime}\right)\right]\right\} \\
& \text { subject to } \\
& c=\alpha K d(\varepsilon)+w(\varepsilon) L(\varepsilon)+\left(\frac{q^{f}(\varepsilon)}{1+a\left(\alpha-\alpha^{\prime}+\theta\right)}\right) K\left(\alpha-\alpha^{\prime}\right)-b^{\prime}+b R \\
& b^{\prime} \geq-\kappa\left(\frac{q^{f}(\varepsilon)}{1+a\left(\alpha-\alpha^{\prime}+\theta\right)}\right) \alpha^{\prime} K
\end{aligned}
$$

The solutions of this problem are represented by the optimal decision rules $\alpha^{\prime}(\alpha, b, \varepsilon)$ and $b^{\prime}(\alpha, b, \varepsilon)$ and the associated optimal consumption plan implied by the budget constraint. The problem is solved by value function iteration using an acceleration routine that splits each set of $n$ iterations so that the first $h$ execute the maximization step in the right-hand-side of the Bellman equation, and the remainder $n$ - $h$ simulate the equation forward using the last iteration's decision rules.

The decision rules that solve problem (23) maximize the utility of domestic agents taking into account the economy's resource constraint, the margin requirement, the optimal rules determining labor, wages, and dividends, the foreign trader's demand function and the market-clearing condition of the asset market. Thus, the prices and allocations supported by the Bellman equation satisfy the 
following properties of the competitive equilibrium: (a) given wages and dividends, $c, b N \alpha$ Nand $L$ solve the constrained maximization problems of households and firms in the domestic economy, (b) given equity prices and dividends, $\alpha N^{*}$ solves the maximization problem of foreign traders, and (c) the market-clearing conditions for equity, goods and labor markets hold.

This recursive representation of the equilibrium has the drawback that the Bellman equation of the domestic economy takes into account the effects of choosing $\alpha_{t+1}$ on the prices $q_{t}$ and $q_{t+1}$ implied by the foreign trader's demand curve, in a way analogous to the problem of a Stackelberg leader that internalizes the demand function of the follower. Mendoza and Smith (2002) proposed an alternative algorithm that avoids this problem by iterating to convergence on pricing functions bid separately by domestic agents and foreign traders. This Tatonnement approach yields a timeconsuming algorithm and computes equilibrium prices with the residual error allowed by the convergence criterion. The algorithm that solves problem (23) is much faster and calculates prices without computational error, but at the cost of adding the "Stackelberg distortions" in the righthand-side of the Euler equation for domestic equity. The results of the quantitative experiments show, however, that these distortions are negligible in the parameter space that we considered.

The distortions are small because, for small per-trade trading costs, the price effects that result from internalizing the foreign traders' demand function are limited to a fraction of the fundamentals price. This can be shown by taking the derivatives of the pricing function implied by the foreign traders' demand curve and simplifying to obtain:

$$
\partial q_{t} / \partial \alpha_{t+1}=z_{t} q_{t}^{f} \geq 0, \quad \partial q_{t+1} / \partial \alpha_{t+1}=-z_{t+1} q_{t+1}^{f} \leq 0
$$

where $z_{t} \equiv a /\left[a\left(\alpha_{t}-\alpha_{t+1}+\theta\right)+1\right]^{2}$. The upper bound of this fraction in the state space $E \times Z$ is $z^{\max }=a /\left[a\left(\chi-\alpha^{\max }+\theta\right)+1\right]^{2}$. In turn, $z^{\max }$ sets upper bounds for the values that the distortions can take and these bounds are small for small $a$ (interestingly, they are also decreasing in $\theta$ ). Moreover, at equilibrium the distortions are much smaller than their upper bounds because the optimal choice of $\alpha_{t+1}$ for any initial state in $E \times Z$ is very unlikely to call for an increase in equity holdings of size $\left(\alpha^{\max }-\chi\right)$. In fact, when margin calls hit it implies reductions in equity holdings.

In the numerical simulations of the next section, we calculated the maximum and the long-run average of the overall distortion produced by the "Stackelberg distortions" in percent of the marginal benefit of investing in equity (i.e., the overall distortion affecting the right-hand-side of the Euler equation (10) as a multiple of $\lambda_{t+1} R_{t+1}^{q}$ ). The majority of the simulations use $a=0.01$, and for these the average and maximum distortions ranged between 0.003 and 0.01 percent. The simulation with the largest per-trade cost uses $a=2$, and in this case the average and maximum distortion were 0.004 and 0.8 percent respectively. These figures compare favorably with the average and maximum errors of the pricing function of 0.007 and 1 percent respectively obtained using the Tatonnement pricingfunction-iteration algorithm in the baseline simulation of Mendoza and Smith (2002). 


\section{Quantitative Predictions of the Stochastic Competitive Equilibrium}

This Section studies the quantitative predictions of the model by examining the results of numerical simulations starting from a baseline case calibrated to Mexican data.

\subsection{Functional Forms and Baseline Calibration}

The numerical analysis uses these functional forms for preferences and technology:

$$
\begin{gathered}
F\left(K, L_{t}\right)=K^{1-\gamma} L_{t}^{\gamma}, \quad 0 \leq \gamma \leq 1 \\
u\left(c_{t}-G\left(L_{t}\right)\right)=\frac{\left[c_{t}-G\left(L_{t}\right)\right]^{1-\sigma}-1}{1-\sigma}, \quad \sigma>1 \\
v\left(c_{t}-G\left(L_{t}\right)\right)=\beta\left[\operatorname{Ln}\left(1+c_{t}-G\left(L_{t}\right)\right)\right], \quad 0<\beta \leq \sigma \\
G\left(L_{t}\right)=\frac{L_{t}^{\delta}}{\delta}, \quad \delta>1
\end{gathered}
$$

The parameter $\gamma$ is the labor income share, $\sigma$ is the coefficient of relative risk aversion, $\beta$ is the elasticity of the rate of time preference with respect to $1+c_{t}-G\left(L_{t}\right)$ and $\delta$ determines the wage elasticity of labor supply (which is equal to $1 /(\delta-1)$ ). The condition $\beta \# \sigma$ is required to satisfy the conditions identified by Epstein (1983) to ensure that SCU yields well-behaved dynamics.

The Markov process of productivity shocks is set so that the standard deviation and firstorder autocorrelation of GDP match the standard deviation and first-order autocorrelation of the HPfiltered quarterly cyclical component of Mexico's GDP reported in Mendoza (2004). In terms of the simple persistence rule defined in equation (4), this requires $\varepsilon_{H}=0.01785$ and $\vartheta=0.683$.

The solution algorithm also needs values for the vectors of preference and technology parameters $[\gamma, \sigma, \beta, \delta, R]$ and financial-frictions parameters $[\kappa, a, \theta]$. Parameter values are assigned following a calibration technique similar to the one used in real business cycle (RBC) theory. RBC calibration sets parameter values so that the deterministic stationary state of a model economy matches observed empirical regularities. Values of preference and technology parameters are relatively easy to set in this way, but the values of financial-frictions parameters are more difficult to determine. This is because margin requirements and short-selling constraints at work in international capital markets are a combination of government regulations and private contractual practices, and trading costs are a mixture of pecuniary and economic costs that are difficult to measure. Hence, the baseline calibration is anchored on a deterministic steady state in which financial frictions are irrelevant. However, since Section 3 showed that portfolio allocations are undetermined in the model's frictionless deterministic stationary equilibrium, the calibration considers instead the case of a "nearly-frictionless economy" (NFE). The NFE steady state is one in which financial-frictions parameters are set so as to yield unique equity and bond positions but yet steady-state allocations and prices are virtually identical to those of the frictionless stationary state.

The calibration yields a deterministic NFE stationary state that replicates Mexico's 1970-95 average GDP shares of private consumption $(s c)$, net exports (snx), investment $(s i)$ and government 
expenditures $(s g)$ at current prices. The ratios obtained using data from the World Bank's Development Indicators are $s c=0.684, s n x=0.007, s i=0.217$, and $s g=0.092$. For the model to mimic $s c$ and $s n x$, it is necessary to make adjustments for investment and government expenditures. The calibration assumes that government expenditures are financed with a constant consumption tax set at $\tau=0.092 / 0.684=0.135$, which is close to Mexico's actual value-added tax rate. This tax vanishes from the Euler equations but it does distort labor supply. Still, keeping the tax state- and timeinvariant implies that its effects on the stochastic dynamics are minimal. To adjust for investment expenditures, the calibration adds an autonomous (time and state invariant) level of private expenditures equal to the fraction si of steady-state output.

The capital stock is normalized at $K=1$ without loss of generality. Mexican data from the System of National Accounts yield an average labor income share for the period 1988-96 of 0.341. However, this is a low labor share compared to evidence from other countries, as has been noted in the controversy surrounding measures of labor income shares in some developing countries (see Mendoza (2004) for the case of Mexico). Hence, we adopted instead a labor share of $\gamma=0.65$, which is more in line with international evidence. Lacking information on the wage elasticity of labor supply, the calibration assumes unitary elasticity, so $\delta=2$. Given $\gamma, K, \tau$ and $\delta$, the steady-state allocations of labor and output and the associated wage and dividend rates are computed using the production function in (25) and the optimality conditions (2), (3) and (9), adjusted for the presence of the consumption tax. Steady-state consumption is then calculated using steady-state output and the requirement that the consumption-GDP ratio matches the average from Mexican data (0.684).

The coefficient of relative risk aversion and the gross real interest rate are set to standard RBC values: $\sigma=2$ and $R=(1.065)^{1 / 4}$. The interest rate and the dividend rate determine then the steady-state fundamentals price $q^{f}=d /(R-1)=16.9$. Finally, given $c, L$ and $\delta$, the value of the time preference elasticity $\beta$ is derived from the steady-state Euler equation for bonds, which implies $\beta=$ $\operatorname{Ln}(R) / \operatorname{Ln}\left(1+c-L^{\delta} / \delta\right)=0.0593$.

Applying the preference and technology parameters set in the previous three paragraphs to the frictionless stationary equilibrium of Section 3, we obtain allocations and prices that match the target national accounts ratios taken from the data, but we also obtain the range of multiple solutions for equity and bond holdings described there. The small open economy borrows from the world credit market (i.e., holds a negative bond position) only in the solutions in this range in which domestic agents own more than 90 percent of the capital stock. Bond holdings become positive and unrealistically large when domestic agents own less than 90 percent of the capital. This is because, with the calibrated parameters, the market value of the capital stock is large relative to steady-state savings (about 11 percent larger). Since bond holdings at the frictionless steady state are given by $\bar{b}=\bar{S}-\bar{q}^{f} \bar{\alpha} K$, it takes only a small reduction in equity holdings (relative to 100-percent ownership) to 
leave households with a positive gap between their desired savings and the value of their equity holdings, which they fill by holding a large bond position. It also follows from this result that it will take low values of $\kappa$ to obtain a binding margin constraint in the NFE steady state. In the frictionless stationary state, the ratio of debt to the value of capital is less than 9.7 percent even in the extreme case in which domestic agents own all the capital. Thus, only values of $\kappa$ below 9.7 percent can result in binding margin constraints in a deterministic stationary equilibrium.

The above findings lead to two important observations. First, the low ratio of debt to capital does not preclude large debt-output ratios. When domestic agents own all the domestic capital stock, the debt ratio is 215 percent of GDP, which is much higher than typical debt ratios of emerging economies (see Lane and Milesi-Ferretti (2001)). Second, a low $\kappa$ can be rationalized as the combined outcome of two features that limit the ability of emerging economies to leverage foreign debt on domestic physical capital: (1) as documented below, the shares of the physical capital stock of an emerging economy that are traded in liquid equity markets often represent a small fraction of the economy's total capital, and (2) of this residual "marketable" portion of the capital stock, only a fraction may be "useful" collateral for external borrowing due to institutional or contractual frictions (see Caballero and Krishnamurty (2001) and Paasche (2001)).

The values of the financial frictions parameters that approximate the frictionless steady-state equilibrium in the NFE case are $a=0.01, \theta=0.04$, and $\kappa=0.09$. In the NFE steady state, the equity price is only 0.04 percent below the fundamentals price, consumption is less than 0.03 percent higher than in the frictionless equilibrium, and the excess return on equity is less than 0.0007 percent. The unique portfolio allocations are $\alpha=0.993$ and $b=-1.51$.

The choice of $\kappa$ at 9 percent follows from the previous result showing that, in the frictionless steady state, the largest ratio of debt to market value of capital is 9.7 percent. The value of $a=0.01$ was chosen to set a high elasticity for the foreign traders' demand curve, so as to approximate an environment without per-trade costs. Given $a=0.01$, the value of $\theta=0.04$ implies a low ratio of steady-state total trading costs to foreign traders' earnings of 7 percent. Thus, foreign traders make substantial gains despite the existence of trading costs.

Before ending the discussion of the calibration procedure, it is important to note that, because the stochastic model is influenced by precautionary saving effects and (if binding) the effects of margin constraints and trading costs, the deterministic stationary equilibria of equity and bonds in the NFE can differ widely from the long-run averages obtained with its stochastic counterpart. For example, the debt ratio in the deterministic NFE is 197 percent but in the stochastic NFE it falls to 130 percent, and in an economy with identical parameters but $\kappa$ set at 4 percent, it falls to only 18 percent. This is not a feature particular to this model. It is a general feature of incomplete-markets models with state-contingent wealth distributions. In calibrating parameter values for models in this 
class, a deterministic steady state is useful for imposing some discipline in the manner in which parameters are selected, but should not be expected to match closely the mean values of state variables in the stochastic steady state as in standard RBC models.

\subsection{State Space for Baseline Simulations}

The baseline simulation results compare the NFE with an economy identical in all respects except for a lower value of $\kappa$ that makes the margin constraint bind in some states of nature. The margin coefficient in the economy with binding margin constraints (BME) is set to $\kappa=0.04$.

These simulations are conducted using a grid of equity positions with 90 evenly-spaced nodes and boundaries set at $\chi=0.75$ and $\alpha^{\max }=1$. The lower bound at 75 percent is higher than the conventional short-selling limit set at 0 but is consistent with the national aggregates targeted in the calibration. In Mexico, the average ratio of stock market capitalization to GDP in the period 19882000 was just 27.6 percent. Since the capital-output ratio is estimated at about 2.5 (see Mendoza (2004)), the total value of the shares of all Mexican publicly-traded firms constitutes just 11 percent of Mexico's capital stock. Thus, a large fraction of Mexico's capital is owned by non-publicly-traded private and government firms and residential property owners, and therefore does not have a liquid market in which shares are traded with foreign residents. Moreover, $\chi=0.75$ is a non-binding lower bound in the stochastic stationary states of the NFE and BME (i.e., the long-run probability of hitting $\chi$ is zero in both cases, as Figure 1a shows).

The 4-percent margin coefficient of the BME is close to a rough estimate of the 1994 ratio of the debt of Mexico's corporations listed in the stock market as a fraction of the country's total capital stock inferred from firm-level data. Calculations based on data from Worldscope show that the median ratio of debt to market value of equity of these corporations was about 30 percent. Since the stock market represents only 11 percent of the nation's capital stock, the debt-equity ratio of listed corporations is about 3.3 percent of Mexico's capital.

The upper bound on equity at 100 percent seems a natural limit of ownership for domestic agents but, because of the market-clearing condition of the equity market, it also implies that foreign traders cannot take short positions (i.e., $\alpha^{*}<0$ is ruled out). However, by design the model makes this constraint irrelevant. In the absence of trading costs, the risk-averse domestic agents would end up selling all their equity to the risk-neutral foreign traders. Per-trade and recurrent trading costs produce long-run equilibria with internal equity positions. If the margin constraint binds, domestic agents "fire-sale" equity, but this again moves the equilibrium towards the lower bound of the equity grid, not the upper bound. Foreign traders sell equity only when the equilibrium price is higher than the fundamentals price, but margin calls and trading costs work to produce prices below the fundamentals price. As a result, $\alpha^{\max }=1$ binds only about 1 percent of the time in the stochastic steady state of the NFE and it never binds in the one for the BME (see Figure 1.a). 
The grid of bond positions includes 150 evenly-spaced nodes. The lower bound, $b^{\text {min }}$, is set to match the largest debt position consistent with the margin constraint for all triples $\left(\alpha^{\prime}, \alpha, \varepsilon\right)$ in the state space (i.e., $\left.b^{\min }=-\kappa q^{\max }\left(\chi, \varepsilon_{H}\right) \alpha^{\max } K=-1.52\right)$. The upper bound $b^{\max }=1.43$ was determined by setting an initial value and changing it gradually until the grid supported the limiting distribution of bonds in both the NFE and BME (see Figure 1b).

\subsection{Comparison of the Baseline NFE \& BME Stochastic Steady States}

The long-run probability distributions of equity and bonds in Figures 1a and 1b show that the distribution of equity (bonds) shifts to the left (right) as a result of the effects of lowering $\kappa$ from 9 percent in the NFE to 4 percent in the BME. These shifts reflect the long-run implications of the changes in the domestic agents' saving and portfolio decisions in the BME. Domestic agents dislike a volatile consumption profile, and this aversion drives them to undertake precautionary saving, require larger risk premia on equity, and fire-sale assets to meet margin calls. Even in the NFE, the model is prone to have domestic agents sell equity at equilibrium in any state in which they demand an equity premium because (with $\theta=0$ ) foreign traders always buy equity at prices that reflect a positive excess return on equity (which are prices below $q_{t}^{f}$ ). Domestic agents then seek to self-insure by building up a large enough bond position. The fire-sales of assets in response to margin calls, and the diminished ability to leverage debt and smooth consumption, in the BME add to the forces driving domestic agents to reduce equity holdings and increase bond holdings.

Precautionary saving behavior produces stochastic stationary states for economies with financial frictions that feature a low probability of observing pairs $(\alpha, b)$ such that a productivity shock can trigger binding margin constraints causing large drops in consumption. The long-run probability of states with binding margin constraints in the BME is 2.45 percent. Moreover, states pairing very large debt positions with low equity positions are ruled out by a version of Aiyagari's (1994) natural debt limit: given the possibility of observing long sequences of adverse shocks, domestic agents never hold portfolios that can lead to $c-G(L)$ becoming non-positive at any time.

The above findings provide an interesting interpretation of the dynamics of emerging economies after the creation of emerging asset markets in the late 1980s, which took place in an environment of high external debts. In the early stage of this financial globalization, in which the model would view the stock of precautionary saving as low relative to its long-run average, emerging economies would be highly vulnerable to suffer endogenous Sudden Stops in response to the "normal" shocks that drive business cycles. Economies that experience favorable shocks as they go through this stage would reach the area of debt-equity positions in which Sudden Stops are rare faster than those hit by adverse shocks. In this early stage the model also predicts high excess returns on emerging markets equity because of the direct, indirect and debt-deflation effects of margin constraints.

Table 2 reports business cycle moments computed using the ergodic distributions of the state 
variables in the NFE and BME. Echoing the results in Mendoza (2002) and (2004), binding margin constraints do not result in large changes in the long-run business cycle behavior of the economy, except for the moments of equity and bonds which change to reflect binding margin constraints and precautionary saving. The mean debt-GDP ratio falls from 129 percent to 18 percent, and the leverage ratio (the ratio of debt to the value of domestic equity holdings) falls from 6 to 0.8 percent. In contrast, the measures of variability, co-movement and persistence of consumption, asset prices and the current account-GDP ratio are almost the same in the two economies, indicating that domestic agents can reshuffle their portfolio and accumulate enough precautionary saving to maintain similar consumption allocations in the long run. Hence, the effects of Sudden Stops are hard to observe in long-run moments and need to be studied by examining short-run dynamics.

Relative to classic RBC models of the small open economy, this model does not produce a stochastic steady state with a counter-cyclical current account. This is a well-known limitation of dynamic general equilibrium models of small open economies that do not consider endogenous capital accumulation, which typically yield pro-cyclical external accounts driven by consumption smoothing (see Mendoza (1991)). The model is also unable to generate endogenous persistence in output fluctuations because the assumptions used to separate the "supply side" from consumption and portfolio choices imply that the persistence of GDP is the same as the persistence of the exogenous productivity shocks. However, the aim of this quantitative analysis is to examine the magnitude of the short-run Sudden Stop effects that can result from margin constraints and trading costs, rather than to develop a full-fledge RBC model. Moreover, since long-run business cycle moments differ little across the NFE and BME, and since this result holds also in RBC models with endogenous investment and financial frictions (as shown in Mendoza (2004)), the inability of this model to produce counter-cyclical external accounts in the long run and to generate endogenous persistence in GDP is not necessarily a major shortcoming. In the short-run Sudden Stop dynamics studied next, there is a strong counter-cyclical response of the current account to adverse productivity shocks.

\subsection{Short-Run Dynamics: Leverage, Liquidity and Sudden Stops}

The previous results showing that the model's financial frictions do not have significant effects on long-run business cycle statistics, and that states with binding margin constraints are low probability events in the stochastic steady state because of precautionary saving, are consistent with the observation that countries do not experience Sudden Stops very often. However, we still need to determine whether the dynamics of the model when the economy does experience a Sudden Stop resemble Sudden Stops observed in the data. This question is examined next by studying the dynamics around the "Sudden Stop region" in which margin constraints bind in the BME.

The Sudden Stop region can be identified by comparing the universe of decision rules for domestic equity in the low-productivity state of the NFE and BME simulations shown in the surface 
plots of Figure 2. The $x$ and $y$ axes represent all the initial states of pairs $(\alpha, b)$ indexed by their position in each grid. The $z$ axis is the value of the decision rule $\alpha^{\prime}\left(\alpha, b, \varepsilon_{L}\right)$, which ranges from 0.75 to 1 (or from $\chi$ to $\alpha^{\max }$ ). Note that, because of the variant of Aiyagari's Natural Debt Limit that holds in this model, the decision rule for the BME is not defined for a triangular area of very low values of equity and bonds. For initial conditions in this area, there is no equity decision rule in the interval $[0.75,1]$, and an associated decision rule for bonds, that support a positive allocation of $c-G(L)$.

Figure 2 shows that, for a given initial equity position, the NFE and BME equity decision rules differ only if there is a sufficiently high level of debt (i.e., low $b$ ). When the state of bond holdings exceeds $b_{60}=-0.35$ (or for debt ratios under 45 percent of average GDP), the decision rules of the NFE and BME become nearly identical for all values of $\alpha$. Hence, the Sudden Stop region is defined by the subset of high-debt bond position $b^{\min } \leq b \leq b_{60}$ for which there is at least one equity position such that the margin constraint binds. Figure 2 shows that in this region the equity and bond decision rules differ sharply across the NFE and BME.

The differences in the equity decision rules inside the Sudden Stop region illustrate the magnitude of the combined direct, indirect, and debt-deflation effects of margin calls. Domestic agents reduce their equity positions significantly more in the BME than in the NFE in response to the same one-standard-deviation productivity shocks and for the same initial bond and equity positions. The largest difference between the two economies is about 6 percent of the capital stock, which occurs for initial states with the highest debt (the smallest $b$ position).

Figures 3-5 "zoom in" on the Sudden Stop region to study differences across the NFE and BME in the impact effects on equity prices, consumption and the current account-GDP ratio in response to a negative, one-standard-deviation productivity shock. The Figures show surface plots similar to Figure 2. The $x$ and $y$ axis are initial states of pairs $(\alpha, b)$ that span the relevant segment of the Sudden Stop region, and the $z$ axis is the impact effect on the corresponding variable as a percent deviation from its long-run average. The plots NFE and BME plots in each Figure use the same scale for the $z$ axis to facilitate comparisons.

Figures 3-5 suggest that the Sudden Stop region can be viewed as composed of three areas that show impact effects of different magnitudes according to the leverage ratio (i.e., the ratio of debt to the market value of equity) and the liquidity of the asset market (i.e., the difference between domestic equity holdings and $\chi$ ) at the initial state. First, if the leverage ratio is high and the asset market is illiquid, domestic agents in the BME have limited capacity to engage in fire sales when margin calls hit, and hence equity prices hardly move and Fisher's debt-deflation mechanism is irrelevant. In this case, margin calls are met mainly by adjusting the debt position sharply, resulting in very large reversals of consumption and the current account. Second, if the leverage ratio is low and there is enough liquidity in the asset market, agents in the BME can sell enough equity to 
achieve a change in the net foreign asset position similar to that of the NFE. ${ }^{11}$ Asset prices fall by more in the BME than in the NFE, but consumption and the current account display very similar responses. Third, if the leverage ratio is high and the asset market has enough liquidity, the direct, indirect and debt-deflation effects of margin calls lead the BME to produce larger price collapses than the NFE together with larger declines in consumption and sizable current account reversals.

Figure 3 shows that the impact effects on asset prices of an adverse productivity shock are significantly more negative in the BME than in the NFE, but the price declines are small compared to those observed in actual Sudden Stops. This is to be expected because of the high elasticity set for the foreign traders' demand curve in the calibration. For the same reason, equity premia are small compared to observed equity premia, even though they are much larger in the BME than in the NFE. These excess returns display the same pattern of the asset price collapses. They are the largest in the area of the Sudden Stop region in which domestic agents liquidate the largest amount of equity.

Figures 3-5 show all the spectrum of possible impact effects at date 1 in response to a negative productivity shock that hits the NFE and BME when the state of equity and bond holdings is inside the Sudden Stop region. The "average" times-series dynamics for 20 quarters after the shock hits are illustrated in Figure 6 for two initial conditions in the relevant areas of the Sudden Stop region: a high-leverage state $(\alpha=0.806, b=-1.481$, with a leverage ratio $b /[q(\alpha, b, \varepsilon) \alpha]=-10.9$ percent $)$ and a lowleverage state $(\alpha=0.806, b=-1.01$, with a leverage ratio of -7.4 percent). Since in these two scenarios $\alpha$ is the same, the level of asset market liquidity is also the same.

Figure 6 plots the differences between the NFE and BME in the forecast functions of consumption, equity prices, and the current account-GDP ratio, as a percent of the long-run averages of each in the NFE. The forecast functions are induced by a negative, one-standard-deviation productivity shock at date 1 , the Markov process of productivity shocks, and the decision rules $\alpha^{\prime}(\alpha, b, \varepsilon)$ and $b^{\prime}(\alpha, b, \varepsilon)$. These forecast functions are analogous to impulse-response functions conditional on starting the NFE and BME at either the high- or low-leverage states and hitting them with the same negative productivity shock. The forecast functions have the advantage that they preserve all the non-linear aspects of the model's stochastic competitive equilibrium captured in the decision rules. The figures plot the difference in the forecast functions between the NFE and BME to remove low-frequency dynamics common to both economies. Since the high- and low-leverage states are far below the long-run averages of equity and bond holdings, the two economies display lowfrequency transitional dynamics to revert all variables to their long-run means.

\footnotetext{
11 This change in portfolio composition also reflects the relative cost of using equity or bonds to smooth consumption. In the absence of margin requirements, equity trading costs lead to intensive trading in bonds (which can be traded at no cost). In contrast, binding margin requirements produce a state-contingent pattern of asset trading. If debt is low, bonds are again traded more actively than equity, but if the economy is highly leveraged the trade-off can change abruptly in favor of equity.
} 
Figure 6 shows that, in the high-leverage state, consumption falls by 5.2 percentage points more in the BME than in the NFE, the current account reversal is equivalent to an increase of 4.1 percentage points of GDP, and asset prices in the BME fall by about four-tenths of a percentage point more than in the NFE. The low-leverage state shows markedly different responses to the same productivity shock. Domestic agents in the BME still liquidate assets to meet margin calls, but now they manage to re-balance their portfolios by replacing debt with reduced equity holdings, and hence they can maintain a net foreign asset position close to the desired one in the NFE. As a result, there is no collapse in consumption and no current account reversal. The asset price decline is slightly smaller than in the high-leverage case. The significant differences in the Sudden Stop dynamics of the high- and low-leverage cases suggest that Fisher's debt-deflation mechanism is a powerful mechanism for inducing strong business cycle amplification even for small asset price changes.

Figure 6 also shows that Sudden Stops are short-lived. In the high-leverage case, it takes about four quarters for the dynamics of consumption, the current account and asset prices of the BME to converge to the patterns of the NFE, and there is already after the first quarter a substantial recovery towards these patterns. Similarly, the price decline in the low-leverage state is reversed after the first quarter. The persistence of Sudden Stops can increase significantly if financial frictions can trigger endogenous persistence mechanisms like those driven by investment dynamics. Mendoza (2004) links margin constraints to the Tobin-Q-determined market value of capital, so that binding margin calls that cause a collapse in the price of capital also cause a collapse in investment, and this increases the persistence of Sudden Stops significantly.

The current account reversal and the drop in consumption in the high-leverage case of Figure 6 are in line with the stylized facts of Sudden Stops in Table 1. Interestingly, the data also show that the two countries with large asset price collapses (Argentina and Mexico) experienced the smallest current account reversals, while Korea displayed the smallest asset price collapse but the largest current account reversal. This is in line with the model's prediction that, examining the impact effects inside the Sudden Stop region in Figures 3 and 5, smaller price adjustments coincide with larger current account reversals. Still, the model misses two important features of Sudden Stops. One feature is the size of the price collapses. As noted earlier, the fall in asset prices is larger in the BME than in the NFE but the high elasticity of the foreign trader's demand curve (i.e., the low value of $a$ ) yields small price declines relative to actual Sudden Stops. The other feature is the large output collapses. However, the model is not designed to explain this feature because of the assumptions of preferences and technology that yield the "supply-side neutrality" isolating output from the effects of financial frictions. Output in this model always responds in the same way to productivity shocks regardless of the values set for all financial frictions parameters.

The extent to which financial frictions amplify cyclical responses in the model is examined in 
more detail by computing initial amplification effects as suggested by Kocherlakota (2000). Kocherlakota argued that, in analyzing the business cycle effects of credit constraints, it is important to separate persistence from amplification. The forecasting functions can be misleading as a measure of amplification because they do not take into account the second moments of the business cycle. Kocherlakota proposed to measure the amplification effect of a once-and-for-all, unanticipated linear income shock that triggers a credit constraint as the difference in a variable observed on impact as the shocks hits under the influence of the credit constraint, relative to the variable's frictionless steady state in percent of the size of the shock. Mendoza (2004) modified this measure for stochastic models in which exogenous shocks follow known random processes (and hence the shocks are to some degree anticipated and recurrent). The modified measure is the difference in the level of a variable between the BME and the NFE in percent of the standard deviation of the variable in the NFE. For example, if the amplification coefficient of consumption for a negative productivity shock is 50 percent, it indicates that the fall in consumption in the BME exceeds that of the NFE by an amount equal to $1 / 2$ the magnitude of an average recession in consumption in the NFE.

Table 3 reports initial amplification effects in consumption, the current account-GDP ratio and equity prices for the high- and low-leverage states of the BME. Amplification effects in the highleverage state are large. The consumption decline at date 1 of a Sudden Stop in the BME, shown in the top chart of Figure 6, is equivalent to three times a typical consumption downturn in the NFE. The current account reversal is 2.6 times larger. In contrast, the low-leverage state shows negligible amplification effects for consumption and the current account. The drop in asset prices is over 40 percent larger in the BME than in the NFE for both the high- and low-leverage states. As noted earlier, prices drop significantly more in the BME than in the NFE, even though in absolute terms (and compared to actual data) the decline is very small.

Sudden Stops in the BME are an endogenous equilibrium outcome of the model. For a given set of parameter values, the model determines whether margin calls occur or not in particular states of nature, and it also determines the magnitude of the resulting effects on portfolio allocations, asset prices, consumption and the current account. This is different from the approach commonly followed in the Sudden Stops literature, which models borrowing constraints as an unanticipated regime change in international capital markets and obtains equilibria in which these constraints always bind (see, for example, Calvo (1998), Paasche (2001) and Christiano et al. (2002)). It is straightforward to approach the simulations of the NFE and BME from this perspective by treating the lower $\kappa$ in the latter as an exogenous, permanent regime change (with the difference that whether the change in $\kappa$ triggers or not margin calls and Sudden Stops is still an endogenous outcome). Alternatively, considering only the BME simulation, one could assume that an exogenous, once-and-for-all shock to debt market access or the world interest rate moves the economy anywhere into the Sudden Stop 
region. In this case, Figures 3-5 show that the model can predict reversals in consumption and the current account ranging from negligible to unrealistically large depending on the leverage ratio and the liquidity of the asset market. Still, accounts of Sudden Stops like these are incomplete inasmuch as they make credit constraints bind by assumption. Agents are suddenly unable to borrow, and their behavior prior to this event is not allowed to depend on the possibility that they may find themselves in this situation. Our results show that, when these assumptions are relaxed, precautionary saving rules out many of the scenarios with large Sudden Stops that can be obtained by imposing exogenous, unanticipated credit constraints.

\subsection{Sensitivity Analysis of Sudden Stop Dynamics}

Table 4 reports Sudden Stop dynamics in response to a negative productivity shock for the baseline calibration and eight alternative scenarios. Each column uses data from two simulations: a nearly-frictionless economy with $\kappa=0.09$ and its counterpart with occasionally binding margin constraints $(\kappa=0.04)$. The Table lists initial responses (i.e., differences in date- 1 forecasting functions between economies with and without margin constraints), amplification effects, long-run probabilities of binding margin constraints, and long-run means and standard deviations of the corresponding economies without margin constraints. The Table illustrates the differences in initial responses and amplification effects across the nine scenarios, and shows whether changes in amplification effects are driven by changes in initial responses or changes in long-run standard deviations.

Table 4 shows that the long-run means of consumption and asset prices in the economies without margin constraints are largely invariant to the parameter changes we considered. The same holds across economies with and without margin constraints for the parameterization in each column of the Table (the means of the latter are omitted to save space). Thus, the result that the long-run averages of consumption and asset prices are invariant to the presence of occasionally binding margin constraints and trading costs is robust to the parameter variations considered in the Table.

Columns II-IV show that simulations with higher autocorrelation and standard deviation of productivity shocks yield higher long-run variability in consumption and asset prices. The higher variability of asset prices in response to these changes is a standard feature of equilibrium asset pricing models that reflects the forward-looking nature of asset prices. Higher consumption variability results from the higher variability of income induced by the exogenous changes in variability or persistence of the shocks, and the endogenous increase in the variability of asset prices. This increased variability of income strengthens incentives for precautionary saving, which lower the long-run probability of binding margin constraints from about 2.5 percent in the baseline to 2 percent in the case with higher persistence of productivity shocks, and 0.8 percent in the case with higher variability of these shocks. Initial consumption and current account responses in the high-leverage state are somewhat stronger in simulations with higher persistence or higher variability of the shocks relative 
to the baseline, but the initial response of asset prices is the same. Amplification effects are somewhat weaker, however, because of the increased variability of macroeconomic aggregates, which more than offsets the stronger initial responses. Initial responses and amplification effects in the low-leverage state with higher persistence or variability of the shocks are nearly the same as in the baseline.

Column V shows that doubling the coefficient of relative risk aversion from 2 to 4 also strengthens precautionary saving incentives, lowering the long-run probability of hitting margin constraints to 1.9 percent. Consumption variability increases but the variability of asset prices is unchanged. The initial responses of consumption and the current account in the high-leverage state increase markedly relative to the baseline (by 2.5 and 2 percentage points respectively), and the amplification effects increase from 3.1 to 4.4 and 2.6 to 5 . The initial response and amplification effect of asset prices remain weak, and again for the low-leverage case changes in initial responses and amplification effects relative to the baseline are negligible.

The above results show that increased variability or persistence in productivity shocks, or a higher degree of risk aversion, produce larger Sudden Stops in consumption and the current account at high leverage ratios than the baseline case, but asset price declines remain small. Moreover, the baseline result showing that at low leverage ratios binding margin constraints trigger price declines of similar magnitude as at high leverage rations, but debt-equity swaps allow adjustments in consumption and net foreign assets similar to those of an economy without margin constraints, is robust to changes in the moments of the shocks or the coefficient of relative risk aversion.

Columns VI-VIII report results for changes in recurrent and per-trade asset trading costs. These changes have negligible effects on the long-run standard deviations of consumption, the current account and asset prices. Hence, changes in amplification effects reflect mainly changes in the magnitude of the initial responses. Recurrent costs set twice as high as in the baseline, at 0.08 , result only in slightly stronger initial responses for consumption and the current account in the highleverage state, and the response of asset prices is unchanged. A lower recurrent cost (at 0.01 ) results in slightly weaker initial responses in consumption and the current account, and again the response of asset prices is unchanged. Changes in initial responses for the low-leverage state relative to the baseline are still negligible. Hence, the results on the magnitude of Sudden Stops derived from the baseline calibration are robust to small variations in recurrent costs. In contrast, the long-run probability of hitting states with binding margin constraints changes significantly: it increases to 7.5 percent with the higher recurrent cost, and falls to a negligible figure with the low recurrent cost.

The reason for the vanishing probability of binding margin constraints in the stochastic steady state of the simulation with $\theta=0.01$ is that this low recurrent cost yields a long-run equilibrium without margin constraints in which domestic agents hold less equity and more bonds on average than in the baseline's NFE: The mean equity holdings (bonds-output ratio) falls (rises) from 0.96 (-1.29) 
in the baseline to 0.85 (1.12) in the simulation without margin constraints and $\theta=0.01$. As a result, the levels of debt produced by a margin constraint with $\kappa=0.04$ have near-zero probability in the simulations with and without margin constraints that use $\theta=0.01$. This result is consistent with the findings derived in the analysis of the deterministic long-run equilibrium, showing that in a frictionless stationary state, steady-state bond holdings become unrealistically large for steady-state equity positions below 90 percent.

The key question that the results in Columns I-VII do not answer is whether the model can produce Sudden Stops that are consistent not only with the observed reversals in consumption and the current account, but also with the collapse in asset prices. Figure 7 and Columns VIII and IX explore this issue. Column VIII increases the per-trade cost coefficient from 0.01 to 0.08 . The results are promising because the magnitude of initial responses of consumption and the current account in the high-leverage state are consistent with actual Sudden Stops, and the price decline, although still small compared to the data, is now about 8 times larger than in Columns I-VII. This results in a large increase in the amplification effect for asset prices, from 0.5 in the baseline to 3.6 in Column VIII, which is due mainly to the stronger initial response (since changes in the standard deviation of asset prices are negligible). Moreover, the responses in the low-leverage state show that asset prices fall by more than in the baseline, and now the reversals in consumption and the current account are larger than in Columns I-VII. Hence, in contrast with the previous results, even at a leverage ratio of -7.4 percent domestic agents cannot fully re-adjust the value of their debt-equity portfolio to prevent a noticeable reversal in their net foreign asset position and a fall in consumption (although both are much smaller than in the high-leverage state).

What values of the per-trade cost would it take for the model to yield a price decline close to those observed in the data? Figure 7 shows that in simulations with $a=1$ or 2 (i.e., price elasticities of the foreign traders' asset demand function of 1 and 1/2 respectively), a high-leverage state yields Sudden Stops in consumption and the current account-GDP ratio larger than those shown in the baseline case of Figure 6, but still in the range of those observed in actual Sudden Stops. In addition, the model now yields substantial declines in asset prices of 4 and 8 percent for the cases with $a=1$ and $a=2$ respectively, and in the latter case the Sudden Stops in consumption and the current account are significantly more persistent (lasting about 10 quarters).

Column IX of Table 4 examines further the results for the economy with $a=2$. As shown in Figure 7, Sudden Stops for a high-leverage state, with a -12.2 percent leverage ratio, feature reversals in consumption and the current account in the range of actual Sudden Stops together with a more realistic price decline of 8.2 percent. As in Column VIII, the initial responses and amplification effects for the low-leverage state (with a -4.3 leverage ratio) are stronger than in the baseline but much weaker than in the high-leverage state. Note, however, that to capture the ergodic distribution of 
this scenario within the same state space as the other simulations of Table 4, and to prevent total trading costs from growing unrealistically large, this scenario lowers the recurrent trading cost to $\theta$ $=0.001$ at the same time that it increases $a$.

The above results show that the model can yield asset price declines close to those observed in the data if the elasticity of demand for the emerging economy's assets is less than unitary. In the model, this elasticity is time-and state-invariant, and determined as the reciprocal of a per-trade trading cost defined as a quadratic function of the size of trades. In general, however, the elasticity of demand for an emerging economy's assets can be influenced by other factors (such as frictions induced by incomplete or imperfect information or search frictions that could affect domestic asset demand by foreign or domestic residents). Moreover, as shown below, trading costs take different forms that may differ from the model's formulation, and these costs are likely to vary with market conditions (for example, increasing in times of turbulence to reflect reduced market liquidity).

It is difficult to assess whether values of $a$ that could support a less-than-unitary demand elasticity in the model's setup of trading costs are in line with actual trading costs. This is in part because the model's quadratic formulation of trading costs does not have a direct empirical counterpart. In addition, actual trading costs are difficult to measure because they include a variety of implicit and explicit costs that differ widely across countries, the class of assets traded, and the conditions of asset markets. The costs include fees such as exchange fees, withholding taxes, shortselling limits, and repatriation limits among others.

One way to measure effective trading costs indirectly is to examine price or return differentials of foreign equities listed in the New York Stock Exchange, NYSE, in the form of American Depository Receipts (ADRs). Several authors have examined these differentials and obtained estimates of sizable effective trading costs. Auguste, Dominguez, Kamil, and Tesar (2004) showed that price differentials between Argentina's ADRs and those in Argentina's stock exchange (Merval) are large and vary widely with market conditions. Argentina's ADRs provided a valuable option for domestic agents to avoid capital controls during the crisis of December, 2001, and hence these ADRs traded at a price discount during the crisis, while before the crisis they traded at a premium of about 0.22 percent. Auguste et al. also reported that trading costs incurred to complete a single transaction of this type, in percent of the market value of the trade, ranged from 0.1 percent for the Merval's trading fee in Argentina to 1.21 percent for the NYSE's charge to Argentinean brokers selling ADRs in New York. In addition, charges like ADR conversion fees increased sharply during the crisis (up to 20 cents on the dollar, compared with a standard fee of 5 cents on the dollar).

Kim, Szakmary and Mathur (2000) estimated implicit trading costs for ADRs of five industrial countries (Australia, Japan, the Netherlands, Sweden, and the U.K.) as the average, risk-adjusted daily excess returns of a portfolio rebalanced optimally across ADRs and a risk-free asset relative to 
buy-and-hold positions in ADRs. The implied quarterly excess returns, assuming 252 trading days per year, ranged from 4.8 percent for Swedish ADRs to 8.1 percent for Australian ADRs. Rabinovitch, Silva and Susmel (2000) obtained comparable estimates of annual excess returns for Argentinean and Chilean ADRs of 40 and 30 percent respectively (8.8 and 6.8 percent quarterly).

A roughly comparable measure of effective trading costs can be obtained from the model by computing total trading costs in percent of equity returns. Figure 8 plots this measure for all $(\alpha, b)$ pairs in the low-productivity state of the simulation with $a=2, \theta=0.001$ and binding margin constraints. Trading costs are negligible, at less than 0.2 percent, outside the Sudden Stop region. Trading costs increase rapidly as the leverage ratio rises inside the Sudden Stop region, reaching a maximum of about 6.4 percent when debt is at its maximum (i.e., $b=b_{1}$ ). Thus, the model yields realistic Sudden Stop dynamics in asset prices, consumption and the current account, in the presence of asset market frictions equivalent to trading costs of at most 6.4 percent of asset returns. Trading costs of this size are in line with the estimates of Kim et al. (2000) and Rabinovitch et al. (2000).

Griffin, Nadari and Stulz (2004) provided further evidence of the potential relevance of trading costs. Using weekly data for the 1993-2003 period, they found that in emerging economies, a one-standard-deviation shock to returns is followed by a 0.60 -standard-deviation increase in trading after five weeks, and that this delayed response is likely due to trading costs. This slow portfolio adjustment is qualitatively consistent with the model's partial-adjustment portfolio rule of foreign traders induced by trading costs. The forecasting functions of the baseline NFE and BME in the highleverage state showed little persistence of asset prices in response to a negative productivity shock (see Figure 6), but asset holdings in the BME drop 4 percentage points below those in the NFE on impact, and take about 20 quarters to converge to the NFE path.

One caveat in interpreting the evidence on trading costs of these empirical studies from the perspective of the model is that in the model trading costs are only incurred by foreign traders. The empirical studies document evidence that trading foreign equities in both the NYSE and the local markets is costly, regardless of the residence of the trading parties. However, the model can also be interpreted more generally: the key to trigger the debt-deflation mechanism is a less-than-perfectly elastic demand for the emerging economy's equity, which can result from trading costs affecting foreign or domestic agents, or from other forms of financial frictions.

\section{Conclusions}

This paper studies the quantitative predictions of a dynamic stochastic general equilibrium asset-pricing model with financial frictions to determine if they can rationalize the Sudden Stop phenomenon of emerging markets crises. The underlying source of uncertainty in the model is a productivity shock of the standard magnitude used in RBC analysis, against which domestic agents cannot hedge because asset markets are incomplete. Two financial frictions are considered. First, 
domestic residents face a collateral constraint in international debt markets, in the form of a margin requirement that limits debt not to exceed the market value of asset holdings used as collateral. Second, foreign traders face trading costs that reflect institutional or informational frictions they encounter in trading the equity of an emerging economy.

Margin calls have direct, indirect and debt-deflation effects working to depress equity prices and increase excess returns. The direct effect is driven by fire-sales of equity in which domestic agents engage to meet margin calls. The indirect effect is induced by the larger consumption volatility and negative covariance between consumption and equity returns that results from the reduced ability to smooth consumption in the presence of current or expected future margin calls. When domestic agents rush to sell equity to meet margin calls, they deal with foreign traders that have a less-thaninfinitely-elastic demand for equity because of trading costs. As a result, equity prices drop and the equity premium rises. In turn, the initial margin call and price drop trigger Fisher's debt-deflation mechanism, as the fall in asset prices leads to subsequent rounds of margin calls. These results require both collateral constraints and trading costs. The former alone cannot induce Sudden Stops because without trading costs the foreign traders' demand function is infinitely elastic at a "fundamentals price" that discounts dividends at the world interest rate.

If the economy has a low leverage ratio (i.e., a low debt-equity ratio), and if the asset market is sufficiently liquid, the asset-price deflation and a large portfolio re-allocation across bonds and equity take place, without impairing too much the domestic agents' ability to adjust their net foreign asset position and smooth consumption. In contrast, if the leverage ratio is high for the same level of asset market liquidity, asset prices still fall but portfolio shifts cannot prevent large reversals in consumption and the current account.

The paper proposes a numerical solution method that solves the competitive equilibrium of the model in recursive form. Numerical simulations based on a calibration to Mexican data illustrate the potential for the interaction of margin calls and trading costs to trigger endogenous Sudden Stops induced by negative productivity shocks of standard magnitude that hit the economy inside the Sudden Stop region of the state space. In this region, external debt is large relative to the value of asset holdings and productivity shocks trigger margin calls. The economy attains these high-debt states as a result of the model's endogenous portfolio dynamics with positive probability even in the long run. Strong incentives for precautionary saving imply, however, that Sudden Stops are low probability events in the stochastic steady state.

The quantitative results show that, even with very small trading costs, the direct, indirect and debt-deflation effects of collateral constraints produce Sudden Stops with large consumption and current account reversals. Asset price declines are small, however, because small per-trade costs imply a high price elasticity for the foreign traders' asset demand function. With trading costs high 
enough to produce demand functions with less-than-unitary price elasticities, the model produces Sudden Stops that feature realistic asset price collapses along with reversals in consumption and the current account in the ranges observed in the data. Moreover, the model's predicted ratio of trading costs to asset returns in this scenario is roughly in line with empirical evidence on trading costs.

The analysis considered only productivity shocks but Sudden Stops can be caused by a variety of foreign and domestic shocks that trigger collateral constraints (e.g. policy shocks, shocks to the terms of trade or to the world interest rate, as in Mendoza (2002) and (2004)). One important finding of this paper is that these shocks need not be unusually large and unanticipated: Adverse shocks of standard magnitude that hit highly-leveraged economies are sufficient to trigger Sudden Stops, and economies reach high-leverage states as a result of endogenous equilibrium dynamics.

The model predicts that Sudden Stops become rare events in the long run, after economies build up buffer stocks of savings. This is an interesting finding in light of the facts that emerging equity markets were created only a decade ago in an environment in which emerging economies were highly indebted, and that in recent years many of them have accumulated large stocks of foreign reserves. The model also predicts that in the early stages of globalization emerging economies are vulnerable to Sudden Stops even in the absence of large systemic shocks to world capital markets, and that during this time emerging economies should command large excess returns.

The model's collateral constraint features a dynamic, non-linear link between asset prices, portfolio choice, and macroeconomic dynamics that can be important for understanding aspects of Sudden Stops not examined in the paper. For example, to the extent that foreign shocks can trigger margin calls, the model embodies a mechanism for the international contagion of Sudden Stops. These shocks could be typical world-interest-rate shocks or shocks like the global margin calls triggered by the Russian default in 1998. Moreover, since occasionally binding credit constraints can lead to distorted asset prices even in states in which the constraints do not bind (as long as they may become binding in the future), they can offer an explanation for the higher volatility of emergingmarkets asset prices relative to industrial-country prices even if actual Sudden Stops are rare.

Further research in the class of models of the one examined here is proceeding in several directions. Cavallo, Perri, Roubini and Kisselev (2002) introduce the "liability dollarization" feature of foreign debt contracts of emerging economies, for which debt is largely denominated in units of tradable goods but leveraged in part on the income and assets of the nontradables sector. Mendoza (2004) studies a model with endogenous capital accumulation to explore output collapses and the investment transmission channel of Sudden Stops. Mendoza and Durdu (2004) study the potential benefits of ex ante official asset price guarantees targeted at offsetting the distortions induced by margin calls and trading costs. 


\section{References}

Aghion, Philippe, Philippe Bacchetta, and Abhijit Banerjee, (2000), "Currency Crises and Monetary Policy with Credit Constraints," mimeo, Dept. of Economics, Harvard University.

Aiyagari, S. Rao (1993), "Explaining Financial Market Facts: The Importance of Incomplete Markets and Transaction Costs." Fed. Reserve Bank of Minneapolis Quarterly Review 17, 17-31. (1994), "Uninsured Idiosyncratic Risk and Aggregate Saving," Quarterly Journal of

Economics, 109(3), 659-684. and Mark Gertler, (1999), "'Overreaction' of Asset Prices in General Equilibrium,"

Review of Economic Dynamics, 2, 3-35.

Auguste, Sebastian, Dominguez, Kathryn M.E., Kamil, Herman and Linda L. Tesar, (2004), "Cross-Border Trading as a Mechanism for Implicit Capital Flight: ADRs, CEDEARs and the Argentine Crisis," mimeo, Department of Economics, University of Michigan.

Arellano, Cristina and Enrique G. Mendoza, (2003), "Credit Frictions and 'Sudden Stops' in Small Open Economies: An Equilibrium Business Cycle Framework for Emerging Markets Crises," in Dynamic Macroeconomic Analysis:Theory and Policy in General Equilibrium, (eds) Altug, Chadha and Nolan, Cambridge University Press.

Auernheimer, Leonardo and Roberto Garcia-Saltos (2000), "International Debt and the Price of Domestic Assets," IMF Working Paper No. WP/00/177, International Monetary Fund.

Backus, David K., Allan W. Gregory and Stanley E. Zin, (1989), "Risk Premiums in the Term Structure: Evidence from Artificial Economies," Journal of Monetary Economies, 24, 371-400.

Bernanke, Ben, Gertler, Mark and Simon Girlchrist, (1998), "The Financial Accelerator in a Quantitative Business Cycle Framework." NBER Working Paper No. 6455, National Bureau of Economic Research, Cambridge: MA.

Caballero, Ricardo J. and Arvind Krishnamurthy (2001), "International and Domestic Collateral Constraints in a Model of Emerging Market Crises," Journal of Monetary Economics, v.48, 513-548.

Calvo, Guillermo A., (1998), " Capital Flows and Capital-Market Crises: The Simple Economics of Sudden Stops," Journal of Applied Economics, v. 1, pp. 35-54

, and Carmen M. Reinhart (1999), "When Capital Inflows come to a Sudden Stop:

Consequences and Policy Options," mimeo, Center for International Economics, Department of Economics, University of Maryland.

, and Enrique G. Mendoza (2000a), "Capital-Markets Crises and Economic Collapse

in Emerging Markets: An Informational-Frictions Approach," American Economic Review: Papers \& Proceedings, May.

, and Enrique G. Mendoza (2000b), "Rational Contagion and the Globalization of Securities Markets," Journal of International Economics, v. 51. Cespedes, Luis, Roberto Chang and Andres Velasco, (2001) "Balance Sheets and Exchange

Rate Policy." Mimeo, Department of Economics, New York University.

Choi, Woon Gyu and David Cook (2004), "Liability Dollarization and the Bank Balance Sheet Channel," Journal of International Economics, 64, no. 2, 247-276.

Coen-Pirani, Daniele (2000), "Margin Requirements and Equilibrium Asset Prices," mimeo,

Graduate School of Industrial Administration, Carnegie Mellon University.

Epstein, Larry G. (1983) "Stationary Cardinal Utility and Optimal Growth under Uncertainty", Journal of Economic Theory, 31, 133-152.

Fisher, Irving, (1933), "The Debt-Deflation Theory of Great Depressions," Econometrica 1, 337-57.

Frankel, Jeffrey A. and Schmukler, Sergio (1996), "Country Fund Discounts and the Mexican Crisis of December 1994," Open Economies Review, Suppl. 1, 7, 551-84

Gopinath, Gita (2003), "Lending Booms, Sharp Reversals and Real Exchange Rate Dynamics," Journal of International Economics. 
Greenwood, Jeremy, Zvi Hercowitz and Gregory W. Huffman (1988), "Investment, Capacity Utilization and the Real Business Cycle," American Economic Review, June.

Griffin, John M., Nardari, Federico and René M. Stulz (2004), "Stock Market Trading and Market Conditions," NBER Working Paper No. 10719, National Bureau of Economic Research.

Heaton, John and Deborah J. Lucas (1996), "Evaluating the Effects of Incomplete Markets on Risk Sharing and Asset Pricing," Journal of Political Economy, 104, no. 3, 443-487.

International Monetary Fund, (1999), International Capital Markets, September, International Monetary Fund, Washington: DC.

Keynes, John Maynard, (1932), "The Consequences to the Banks of the Collapse of Money Value." ch. 7 of Essays in Persuasion, Harcourt, Brace and Company: New York, NY.

Kiyotaki, Nobuhiro and John Moore, (1997), "Credit Cycles," Journal of Political Economy, v. $105,211-248$.

Kim, Minho, Szakmary, Andrew, C. and Ike Mathur, (2000), "Price Transmission Dynamics Between ADRs and their Underlying Foreign Securities," Journal of Banking \& Finance, 24, 13591382.

Kocherlakota, Narayana (2000) "Creating Business Cycles Through Credit Constraints," Federal Reserve Bank of Minneapolis Quarterly Review, v. 24, no. 3, Summer, 2-10.

Krusell, Per and Anthony A. Smith Jr., (1997), "Income and Wealth Heterogeneity, Portfolio Choice, and Equilibrium Asset Returns," Macroeconomic Dynamics, 1, 387-422.

Lane, Philip R. and Gian Maria Milesi-Ferretti, (2001), "The External Wealth of Nations: Measures of Foreign Assets and Liabilities for Industrial and Developing Countries," Journal of International Economics, 55, 263-294.

Lucas, Deborah J. (1994) "Asset Pricing with Undiversifiable Income Risk and Short Sales Constraints," Journal of Monetary Economics, 34, 325-41.

Martin, Philippe and Helene Rey (2002), "Financial Globalization and Emerging Markets: With or Without Crash?," mimeo, Department of Economics, Princeton University.

Mendoza, Enrique G., (1991), "Real Business Cycles in a Small Open Economy," American Economic Review, 81, 797-818.

(2002), "Credit, Prices, and Crashes: Business Cycles with a Sudden Stop," in

Preventing Currency Crises in Emerging Markets, ed. by S. Edwards and J. Frankel, University of Chicago Press.

(2004), “'Sudden Stops' in an Equilibrium Business Cycle Model with Credit Constraints: A Fisherian Deflation of Tobin's q," mimeo, Department of Economics, University of Maryland.

and Katherine A. Smith (2002), "Margin Calls, Trading Costs and Asset Prices in Emerging Markets: the Financial Mechanics of the 'Sudden Stop' Phenomenon," NBER Working Paper No. 9286, National Bureau of Economic Research.

and Ceyhun Bora Durdu, (2004), "Putting the Brakes on Sudden Stops: The Financial

Frictions-Moral Hazard Tradeoff of Asset Price Guarantees," NBER Working Paper No. , National Bureau of Economic Research, Cambridge:MA.

Obstfeld, Maurice (1982), "Aggregate Spending and the Terms of Trade: Is There a LaursenMetzler Effect," Quarterly Journal of Economics, , 97, 251-270.

Paasche, Bernhard, (2001), "Credit Constraints and International Financial Crises," Journal of Monetary Economics, v.28, 623-650.

Rabinovitch, Ramon, Silva, Ana C., and Raul Susmel, (2000), "The Impact of Capital Controls and Transaction Costs on the Return Distribution of Dually Traded Securities: Evidence from Chile and Argentina," Department of Finance, CBA, University of Houston. 
Table 1. Sudden Stops in Four Emerging Economies

\begin{tabular}{|c|c|c|c|c|}
\hline & $\begin{array}{l}\text { Real Equity Prices } \\
\text { (percent change) }\end{array}$ & $\begin{array}{l}\text { Current Account-GDP Ratio } \\
\text { (percentage points change) }\end{array}$ & $\begin{array}{l}\text { Industrial Production } \\
\text { (percent change) }\end{array}$ & $\begin{array}{l}\text { Private Consumption } \\
\text { (percent change) }\end{array}$ \\
\hline Argentina (94.4-95.1) & -27.82 & 4.05 & -9.26 & -4.12 \\
\hline Korea (97.4-98.1) & -9.79 & 10.97 & -7.20 & -9.48 \\
\hline
\end{tabular}

Note: Real equity prices are deflated by the CPI, except Russian equity prices which are in U.S. dollar terms. The change in the current account-GDP ratio for Argentina corresponds to the second quarter of 1995. Industrial production for Korea and Russia and private consumtpion for Argentina, Korea, and Russia are annual rates. 
Table 2. Long-run Business Cycle Moments

\begin{tabular}{|c|c|c|c|c|c|}
\hline variable & mean & $\begin{array}{c}\text { standard } \\
\text { deviation } \\
\text { (In percent) }\end{array}$ & $\begin{array}{c}\text { standard } \\
\text { deviation } \\
\text { relative to GDP }\end{array}$ & $\begin{array}{c}\text { correlation } \\
\text { with } \\
\text { GDP } \\
\end{array}$ & $\begin{array}{l}\text { first-order } \\
\quad \text { auto } \\
\text { correlation }\end{array}$ \\
\hline \multicolumn{6}{|l|}{ I. Nearly Frictionless Economy } \\
\hline GDP & 0.765 & 2.644 & 1.000 & 1.000 & 0.683 \\
\hline consumption & 0.523 & 1.685 & 0.436 & 0.839 & 0.809 \\
\hline current account - GDP ratio & -0.0004 & 1.591 & 0.787 & 0.985 & 0.671 \\
\hline trade balance - GDP ratio & 0.316 & 1.050 & 0.519 & 0.802 & 0.737 \\
\hline equity price & 16.863 & 0.085 & 0.710 & 0.999 & 0.684 \\
\hline foreign debt - GDP ratio & 1.293 & 50.564 & 25.003 & 0.305 & 0.979 \\
\hline debt - equity ratio & 0.060 & 2.278 & 1.127 & 0.244 & 0.983 \\
\hline II. Economy with Financial Frictions & \multicolumn{5}{|c|}{ Long run probability of binding margin constraint 2.45 perceni } \\
\hline GDP & 0.765 & 2.644 & 1.000 & 1.000 & 0.683 \\
\hline consumption & 0.523 & 1.677 & 0.434 & 0.850 & 0.803 \\
\hline current account - GDP ratio & -0.0004 & 1.533 & 0.758 & 0.984 & 0.670 \\
\hline trade balance - GDP ratio & 0.316 & 1.030 & 0.509 & 0.810 & 0.732 \\
\hline equity price & 16.863 & 0.085 & 0.712 & 0.999 & 0.684 \\
\hline foreign debt - GDP ratio & 0.181 & 45.008 & 22.255 & 0.238 & 0.983 \\
\hline debt - equity ratio & 0.008 & 2.250 & 1.113 & 0.227 & 0.983 \\
\hline
\end{tabular}

Table 3. Initial Amplification Effect of a Negative, One-Standard-Deviation Productivity Shock

\begin{tabular}{lcc}
\hline & high leverage state & low leverage state \\
variable & $\begin{array}{c}-10.9 \% \text { leverage ratio } \\
(\alpha=0.806, b=-1.481)\end{array}$ & $\begin{array}{c}-7.4 \% \text { leverage ratio } \\
(\alpha=0.806, b=-1.005)\end{array}$ \\
\hline consumption & 3.111 & 0.107 \\
current account - GDP ratio & 2.627 & 0.090 \\
equity price & 0.461 & 0.428 \\
\hline
\end{tabular}


Table 4. Sensitivity Analysis of Initial Responses and Amplification Effects in Response to a Negative, One-Standard-Deviation Productivity Shock

\begin{tabular}{|c|c|c|c|c|c|c|c|c|c|}
\hline & \multirow{2}{*}{$\frac{\text { Baseline }}{\text { (I) }}$} & \multicolumn{3}{|c|}{ Shock size and persistence } & \multirow[b]{2}{*}{$\begin{array}{c}\text { Preferences } \\
(\mathbf{V}) \\
\text { higher CRRA } \\
\text { coefficient } \\
\gamma=4\end{array}$} & \multicolumn{3}{|c|}{ Trading costs parameters } & \multirow{2}{*}{$\begin{array}{l}\text { Large price } \\
\text { response 1/ } \\
\text { (IX) } \\
\begin{array}{c}a=2 \\
\theta=0.001\end{array}\end{array}$} \\
\hline & & $\begin{array}{c}\text { (II) } \\
\text { lower } \\
\text { autocorrelation } \\
\vartheta=0.5\end{array}$ & $\begin{array}{c}\text { (III) } \\
\text { higher } \\
\text { autocorrelation } \\
\vartheta=0.8\end{array}$ & $\begin{array}{c}\text { (IV) } \\
\text { higher } \\
\text { standard dev. } \\
\varepsilon_{H}=2.4 \% \\
\end{array}$ & & $\begin{array}{c}(\mathbf{V I}) \\
\text { higher } \\
\text { recurrent cost } \\
\theta=0.08\end{array}$ & $\begin{array}{c}\text { (VII) } \\
\text { lower } \\
\text { recurrent cost } \\
\theta=0.01\end{array}$ & $\begin{array}{c}\text { (VIII) } \\
\text { higher } \\
\text { per-trade cost } \\
a=0.08\end{array}$ & \\
\hline $\begin{array}{l}\text { Initial responses (in percent of } \\
\text { A) High leverage ratio }(-10.9 \%)\end{array}$ & un mean in & he correspondi & ng economy w & th non-bindin & argin constra & & & & \\
\hline $\begin{array}{l}\text { consumption } \\
\text { current account - GDP ratio } \\
\text { equity price }\end{array}$ & $\begin{array}{l}-5.24 \\
4.18 \\
-0.04\end{array}$ & $\begin{array}{c}-5.19 \\
4.14 \\
-0.04\end{array}$ & $\begin{array}{c}-5.32 \\
4.24 \\
-0.04\end{array}$ & $\begin{array}{c}-6.56 \\
5.28 \\
-0.04\end{array}$ & $\begin{array}{c}-7.83 \\
6.25 \\
-0.03\end{array}$ & $\begin{array}{l}-5.29 \\
4.22 \\
-0.04\end{array}$ & $\begin{array}{l}-5.21 \\
4.15 \\
-0.04\end{array}$ & $\begin{array}{l}-6.11 \\
4.88 \\
-0.31\end{array}$ & $\begin{array}{l}-7.49 \\
5.97 \\
-8.16\end{array}$ \\
\hline $\begin{array}{l}\text { B) Low leverage ratio }(-7.4 \%) \\
\text { consumption } \\
\text { current account - GDP ratio } \\
\text { equity price }\end{array}$ & $\begin{array}{r}0.18 \\
-0.14 \\
-0.04\end{array}$ & $\begin{array}{r}0.23 \\
-0.18 \\
-0.04\end{array}$ & $\begin{array}{l}0.11 \\
-0.09 \\
-0.04\end{array}$ & $\begin{array}{l}-0.40 \\
0.32 \\
-0.03\end{array}$ & $\begin{array}{r}0.18 \\
-0.15 \\
-0.04\end{array}$ & $\begin{array}{r}0.14 \\
-0.11 \\
-0.04\end{array}$ & $\begin{array}{r}0.21 \\
-0.17 \\
-0.04\end{array}$ & $\begin{array}{r}-1.57 \\
1.25 \\
-0.27\end{array}$ & $\begin{array}{c}-2.09 \\
1.67 \\
-0.56\end{array}$ \\
\hline $\begin{array}{l}\text { Amplification Effects (absolute } \\
\text { A) High leverage ratio (-10.9\%) } \\
\text { consumption } \\
\text { current account - GDP ratio } \\
\text { equity price }\end{array}$ & $\begin{array}{l}3.11 \\
2.63 \\
0.46\end{array}$ & $\begin{array}{l}3.46 \\
2.51 \\
1.00\end{array}$ & $\begin{array}{l}2.79 \\
2.81 \\
0.25\end{array}$ & $\begin{array}{l}2.99 \\
2.48 \\
0.31\end{array}$ & $\begin{array}{l}4.40 \\
5.02 \\
0.39\end{array}$ & $\begin{array}{l}3.15 \\
2.60 \\
0.46\end{array}$ & $\begin{array}{l}3.22 \\
2.73 \\
0.46\end{array}$ & $\begin{array}{l}3.54 \\
3.05 \\
3.57\end{array}$ & $\begin{array}{c}4.65 \\
2.45 \\
94.79\end{array}$ \\
\hline $\begin{array}{l}\text { B) Low leverage ratio }(-7.4 \%) \\
\text { consumption } \\
\text { current account - GDP ratio } \\
\text { equity price }\end{array}$ & $\begin{array}{l}0.11 \\
0.09 \\
0.43\end{array}$ & $\begin{array}{l}0.15 \\
0.11 \\
0.93\end{array}$ & $\begin{array}{l}0.06 \\
0.06 \\
0.23\end{array}$ & $\begin{array}{l}0.18 \\
0.15 \\
0.24\end{array}$ & $\begin{array}{l}0.10 \\
0.12 \\
0.43\end{array}$ & $\begin{array}{l}0.08 \\
0.07 \\
0.42\end{array}$ & $\begin{array}{l}0.13 \\
0.11 \\
0.43\end{array}$ & $\begin{array}{l}0.91 \\
0.78 \\
3.07\end{array}$ & $\begin{array}{l}1.30 \\
0.68 \\
6.47\end{array}$ \\
\hline $\begin{array}{l}\text { Long run probability of binding } \\
\text { margin constraint (\%) }\end{array}$ & 2.45 & 3.88 & 1.99 & 0.83 & 1.92 & 7.55 & 0.001 & 10.30 & 2.45 \\
\hline $\begin{array}{l}\text { Long-run means in economies } \\
\text { consumption } \\
\text { equity price }\end{array}$ & $\begin{array}{l}\text { on-binding } \\
0.523 \\
16.863\end{array}$ & $\begin{array}{c}\text { nargin constrai } \\
0.523 \\
16.863\end{array}$ & $\begin{array}{c}\boldsymbol{n t}(\boldsymbol{\kappa}=\mathbf{0 . 9 1 )} \\
0.523 \\
16.863\end{array}$ & $\begin{array}{c}0.523 \\
16.865\end{array}$ & $\begin{array}{c}0.524 \\
16.863\end{array}$ & $\begin{array}{c}0.523 \\
16.857\end{array}$ & $\begin{array}{c}0.523 \\
16.869\end{array}$ & $\begin{array}{c}0.524 \\
16.816\end{array}$ & $\begin{array}{c}0.523 \\
16.837\end{array}$ \\
\hline $\begin{array}{l}\text { Long-run standard deviations } \\
\text { consumption } \\
\text { current account GDP ratio } \\
\text { equity price }\end{array}$ & $\begin{array}{c}\text { Tomies wit } \\
0.0088 \\
0.0159 \\
0.0144\end{array}$ & $\begin{array}{c}\text { Ton-binding ma } \\
0.0079 \\
0.0165 \\
0.0066\end{array}$ & $\begin{array}{c}\text { rgin constrain } \\
0.0100 \\
0.0151 \\
0.0262\end{array}$ & $\begin{array}{r}(\kappa=0.91) \\
0.0115 \\
0.0213 \\
0.0199\end{array}$ & $\begin{array}{l}0.0093 \\
0.0124 \\
0.0144\end{array}$ & $\begin{array}{l}0.0088 \\
0.0162 \\
0.0145\end{array}$ & $\begin{array}{l}0.0085 \\
0.0152 \\
0.0144\end{array}$ & $\begin{array}{l}0.0090 \\
0.0160 \\
0.0147\end{array}$ & $\begin{array}{l}0.0084 \\
0.0244 \\
0.0145\end{array}$ \\
\hline
\end{tabular}


Figure 1a. Lon-run Distributions of Domestic Equity Holdings

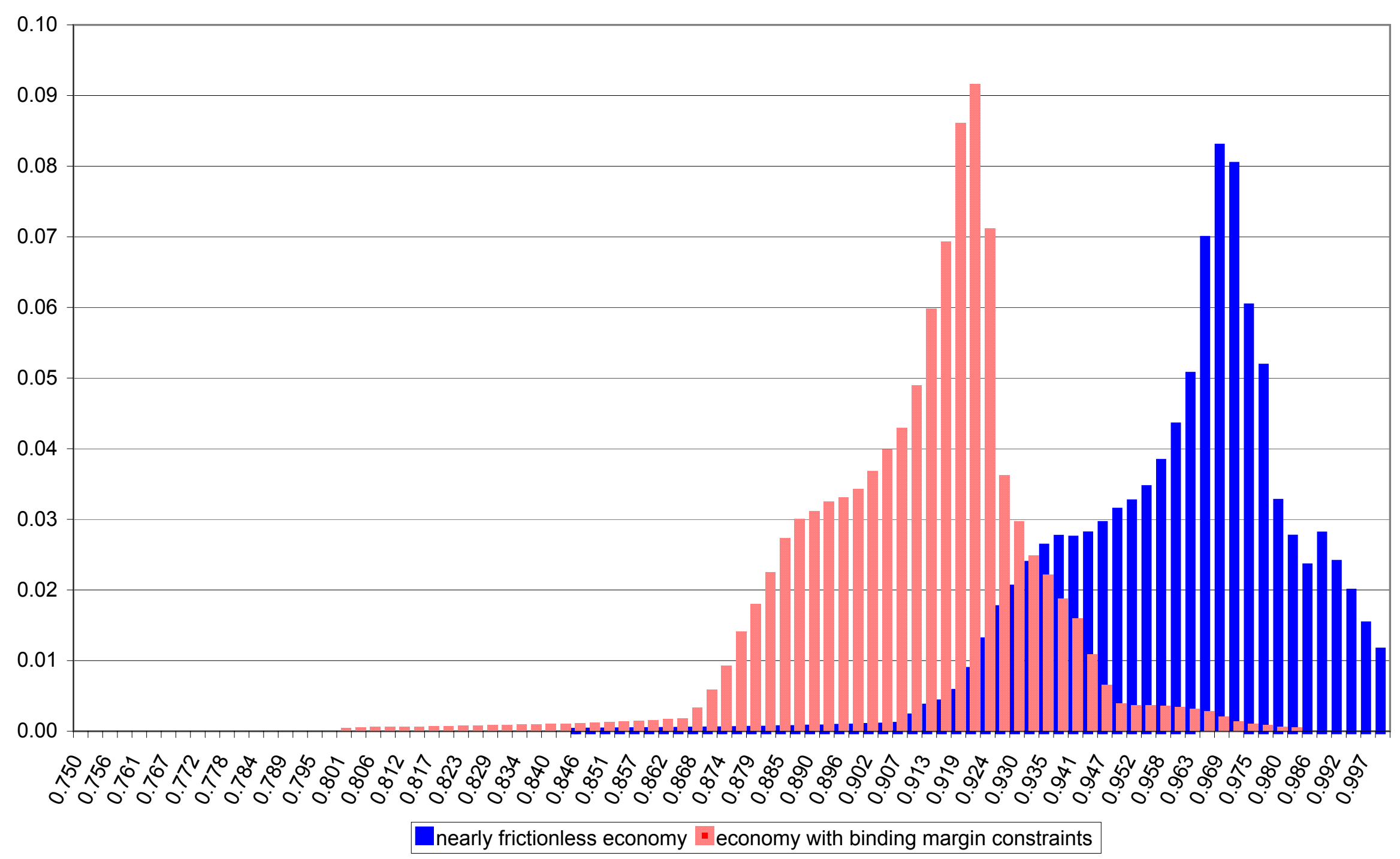


Figure 1b. Long-run Distributions of International Bonds

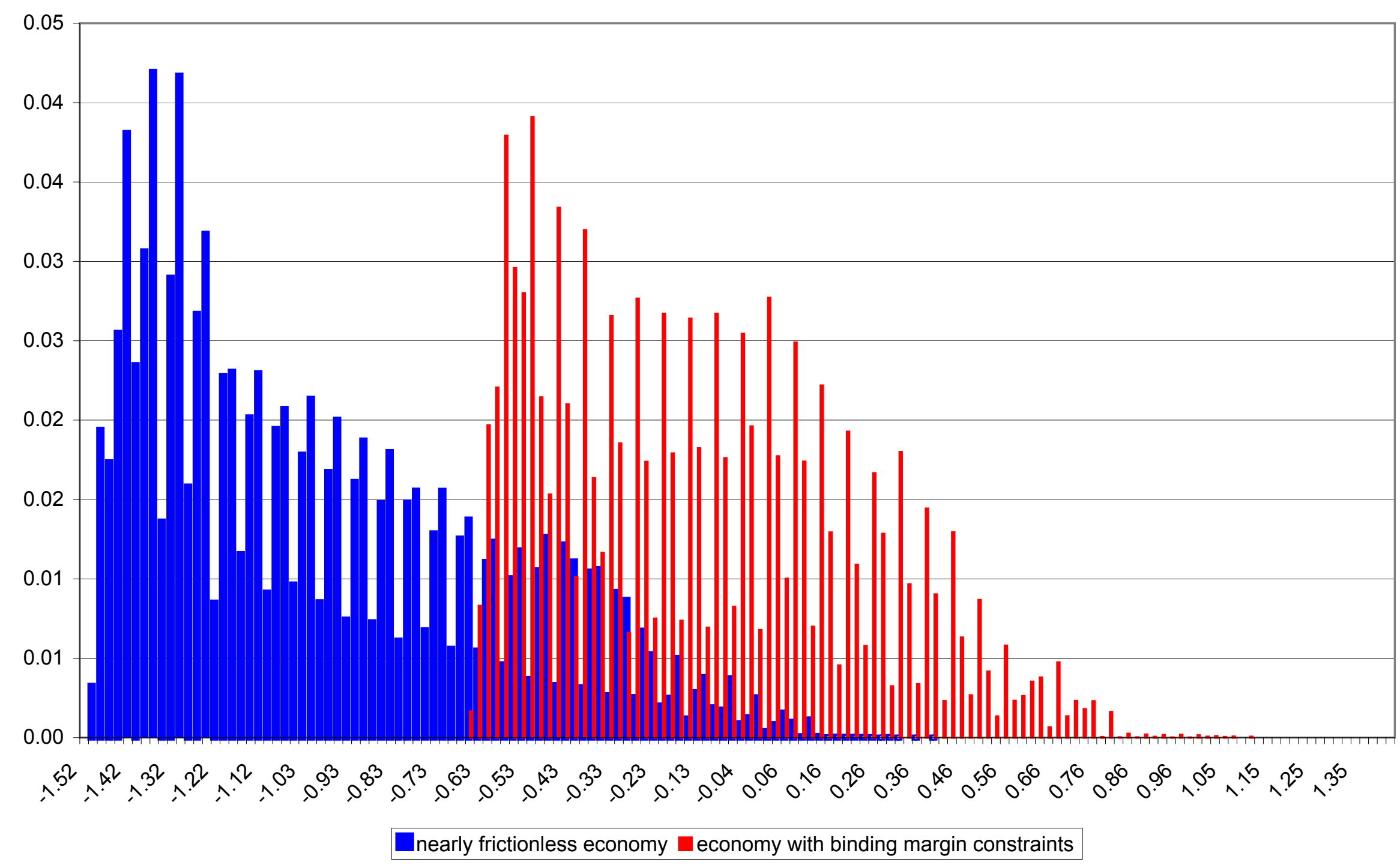


Figure 2. Equity Decision Rules in the Low Productivity State
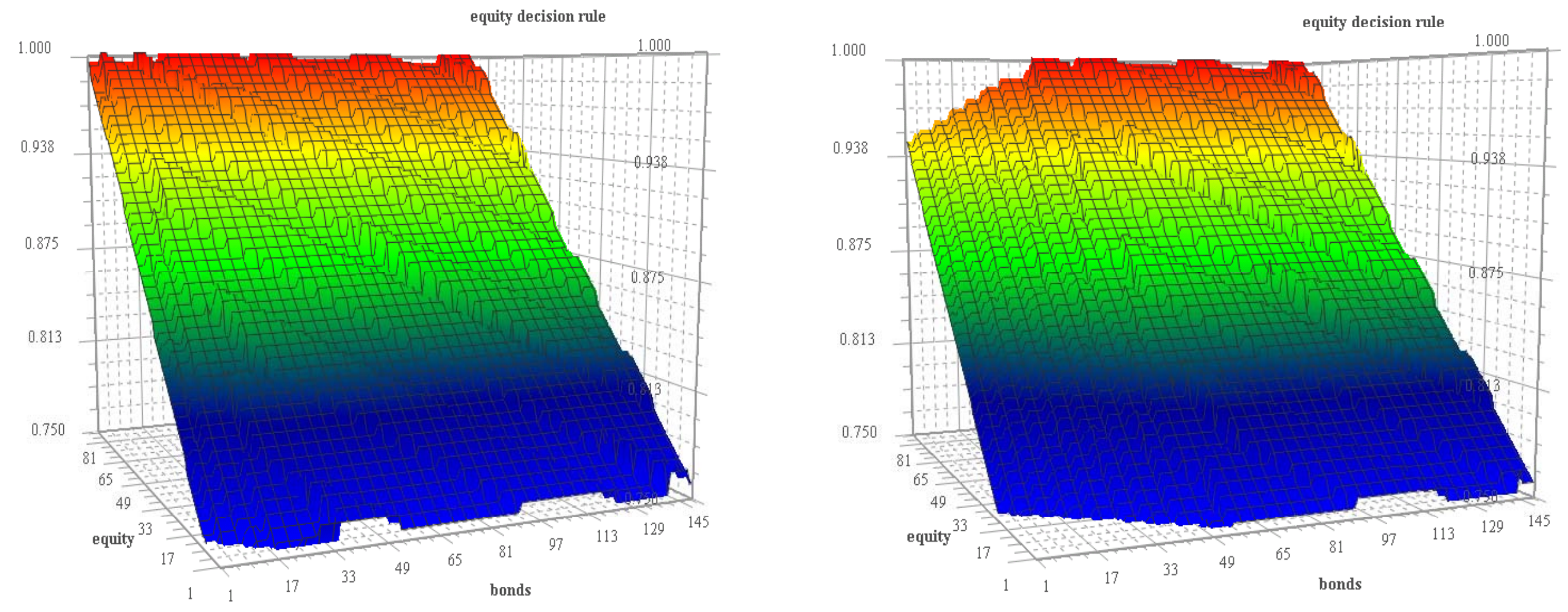

a. nearly-frictionless economy

b. economy with binding margin constraints 
Figure 3. Equity Price Impact Effects in Response to One-Standard-Deviation Productivity Shock

$\%$ deviation from mean

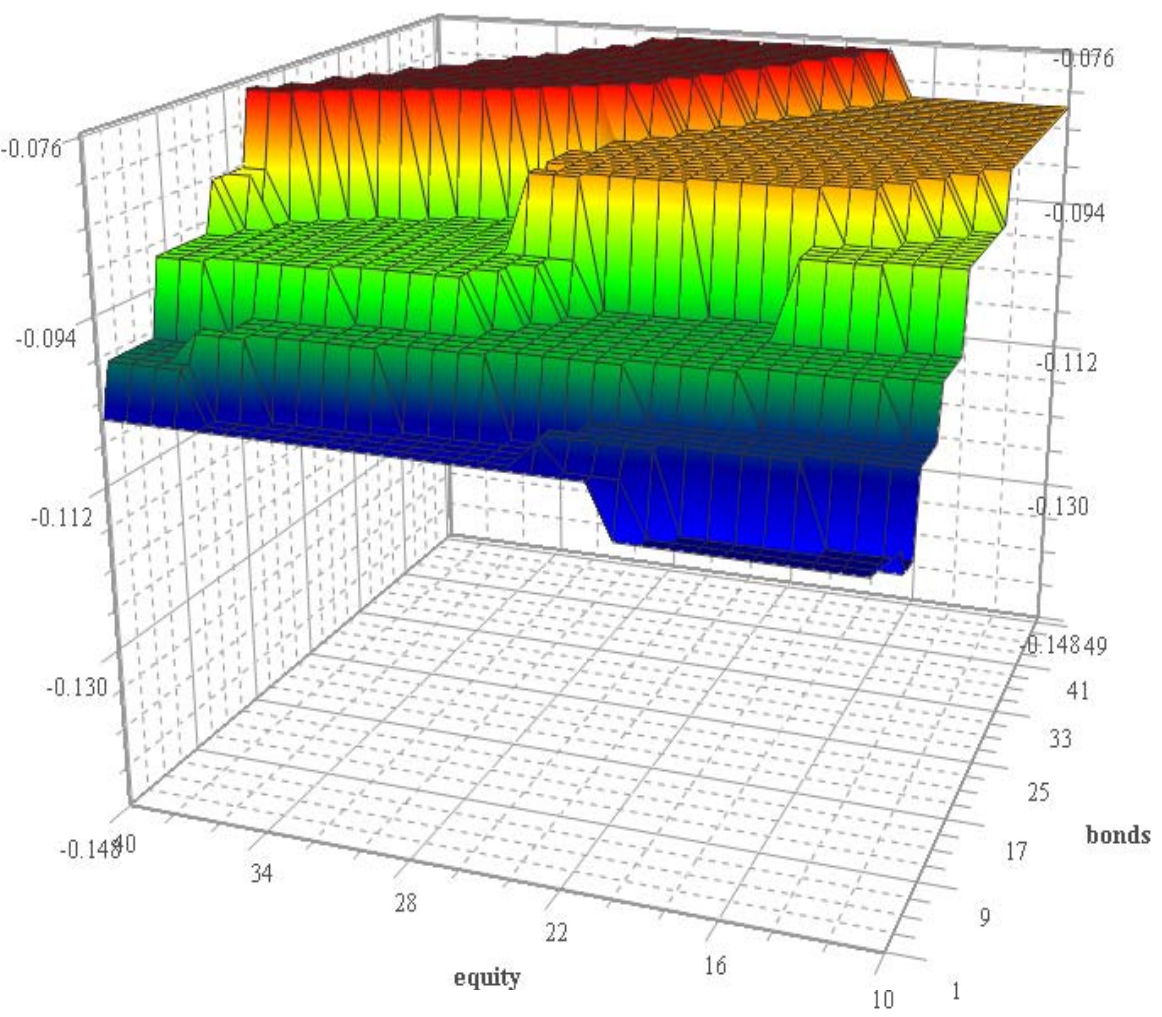

a. nearly-frictionless economy
$\%$ deviation from mean

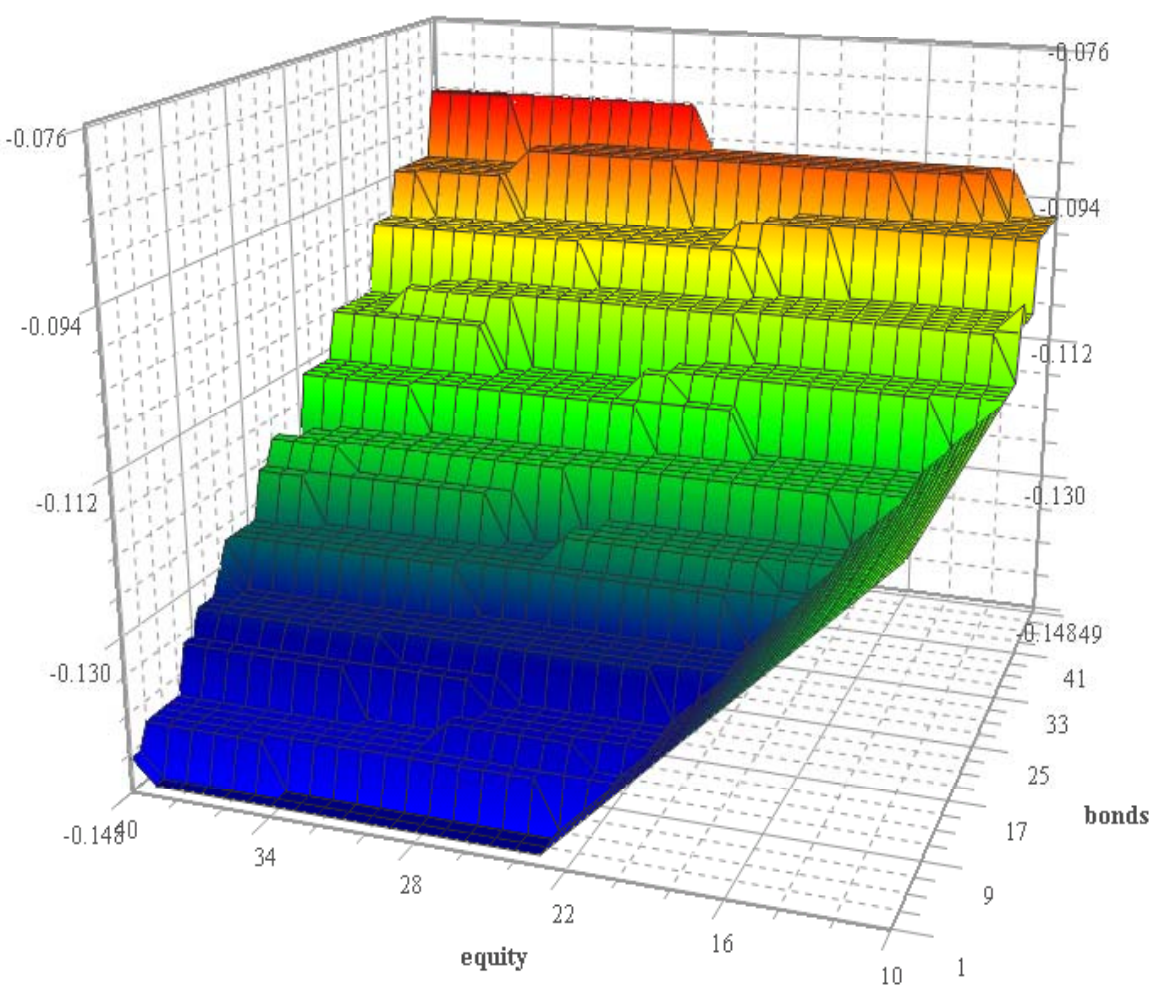

b. economy with binding margin constraints 
Figure 4. Consumption Impact Effects in Response to One-Standard-Deviation Productivity Shock

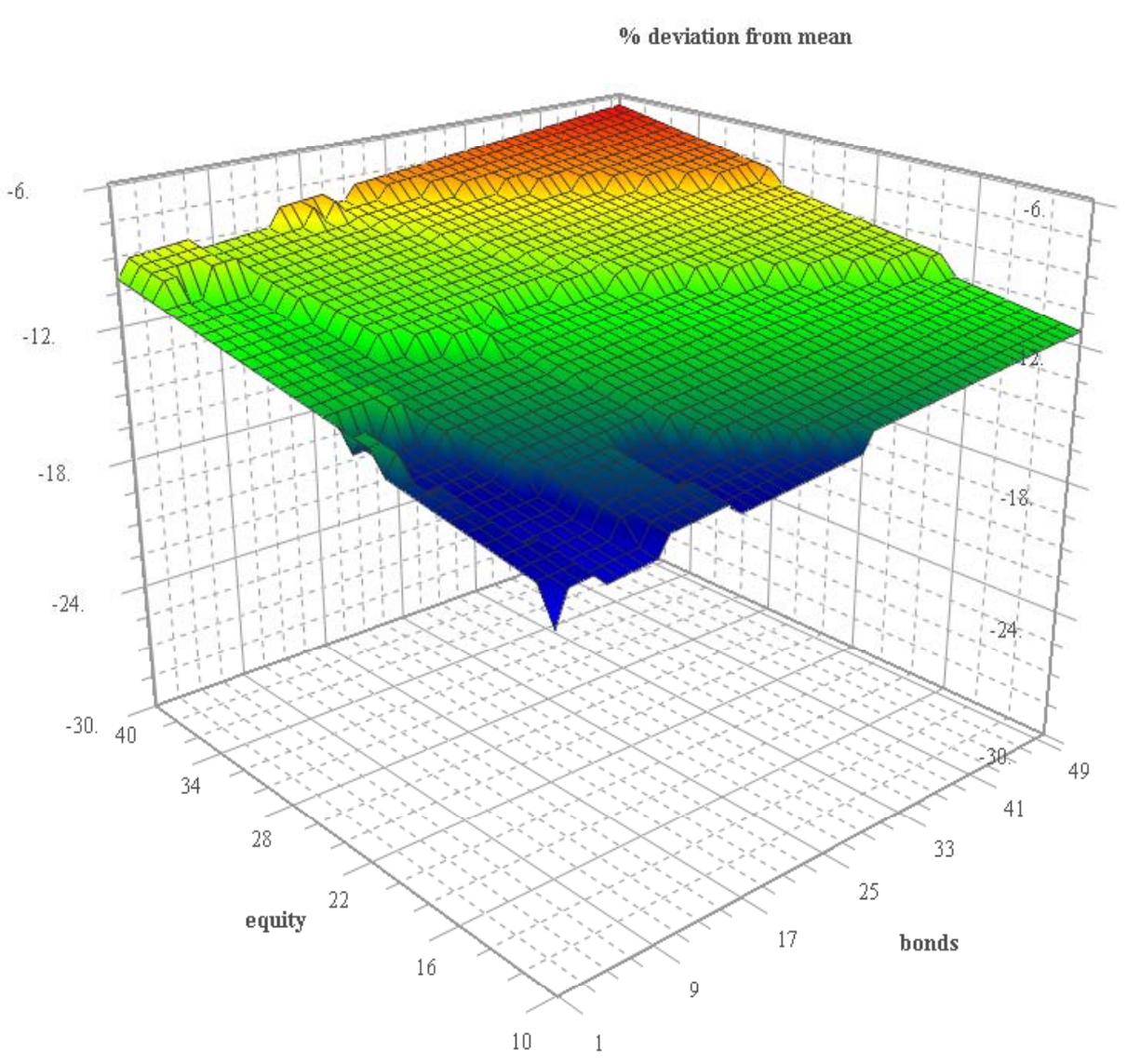

a. nearly-frictionless economy

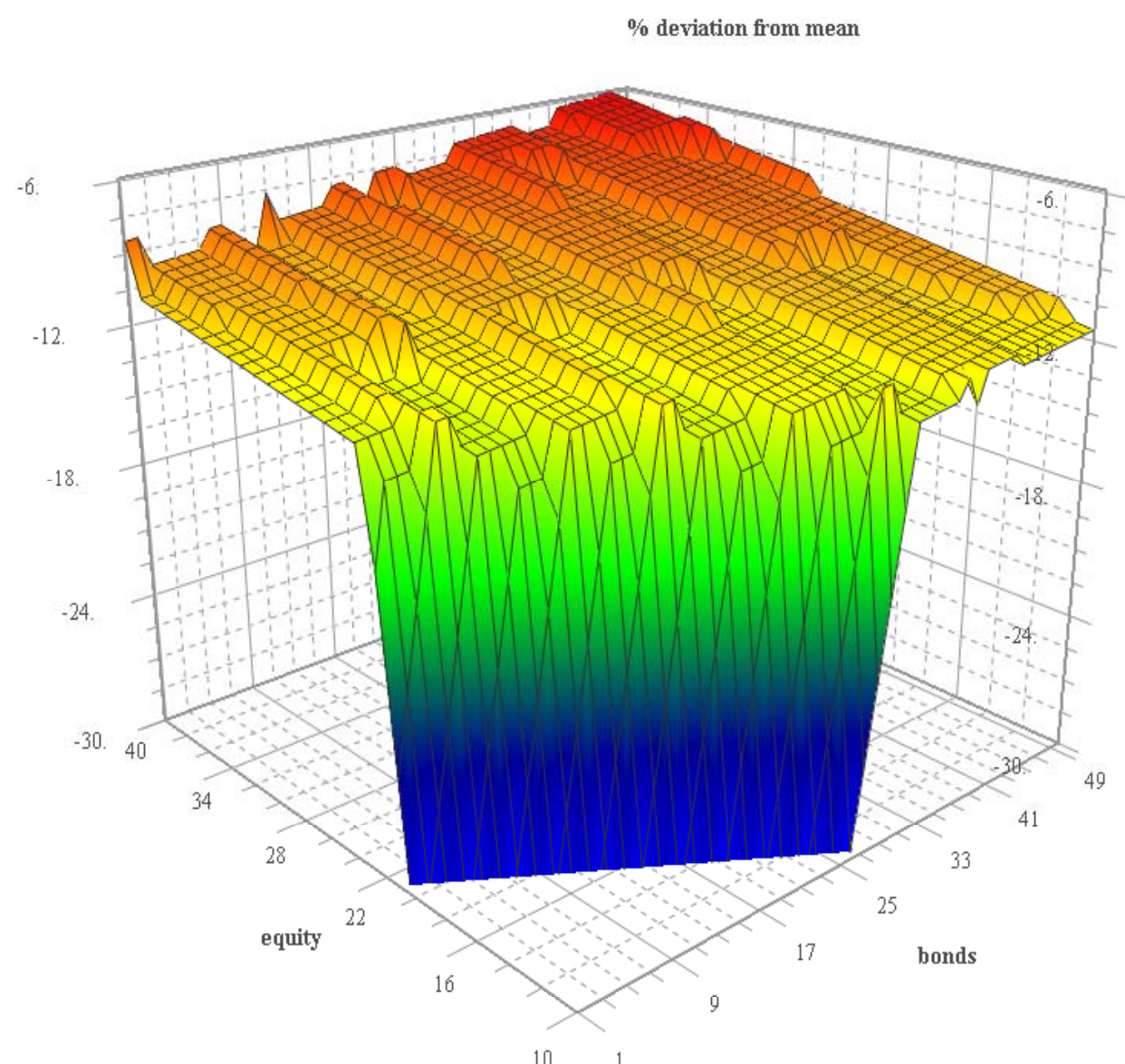

b. economy with binding margin constraints 
Figure 5. Current Account-Output Ratio Impact Effects in Response to One-Standard-Deviation Productivity Shock

$\%$ deviation from mean

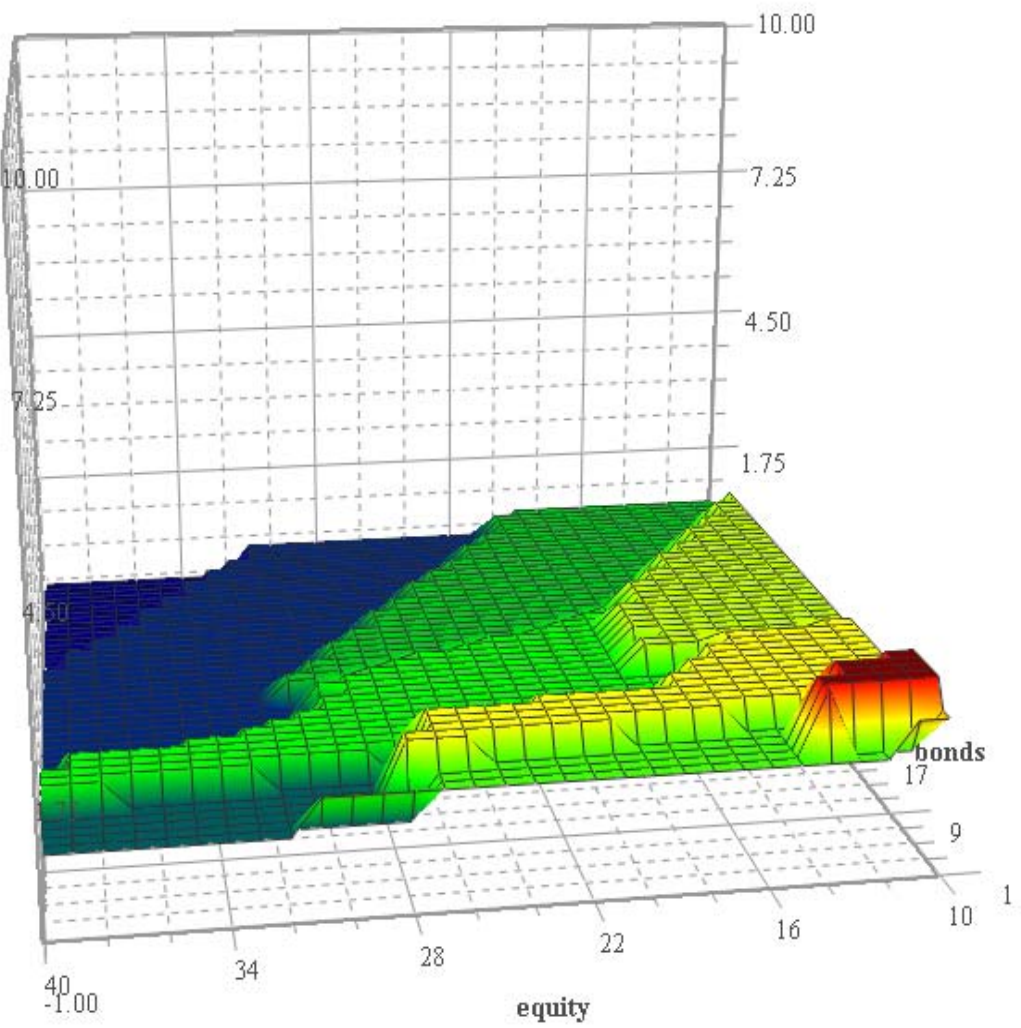

a. nearly-frictionless economy

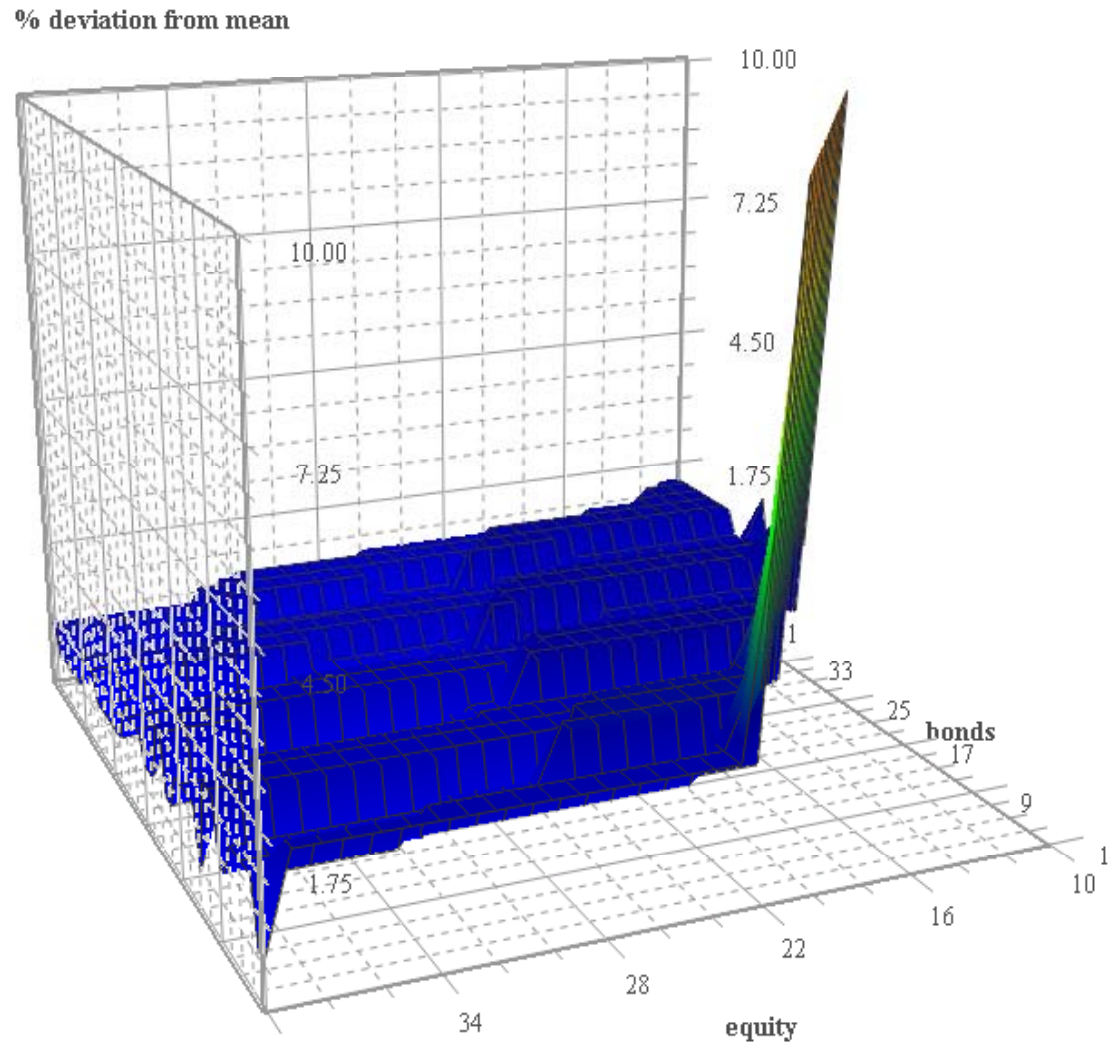

$40-1.00$

b. economy with binding margin constraints 
Figure 6. Sudden Stop Dynamics in Response to a Productivity Shock for Initial States with High and Low Leverage Ratios (differences in forecasting functions across economies with and without margin constraints)
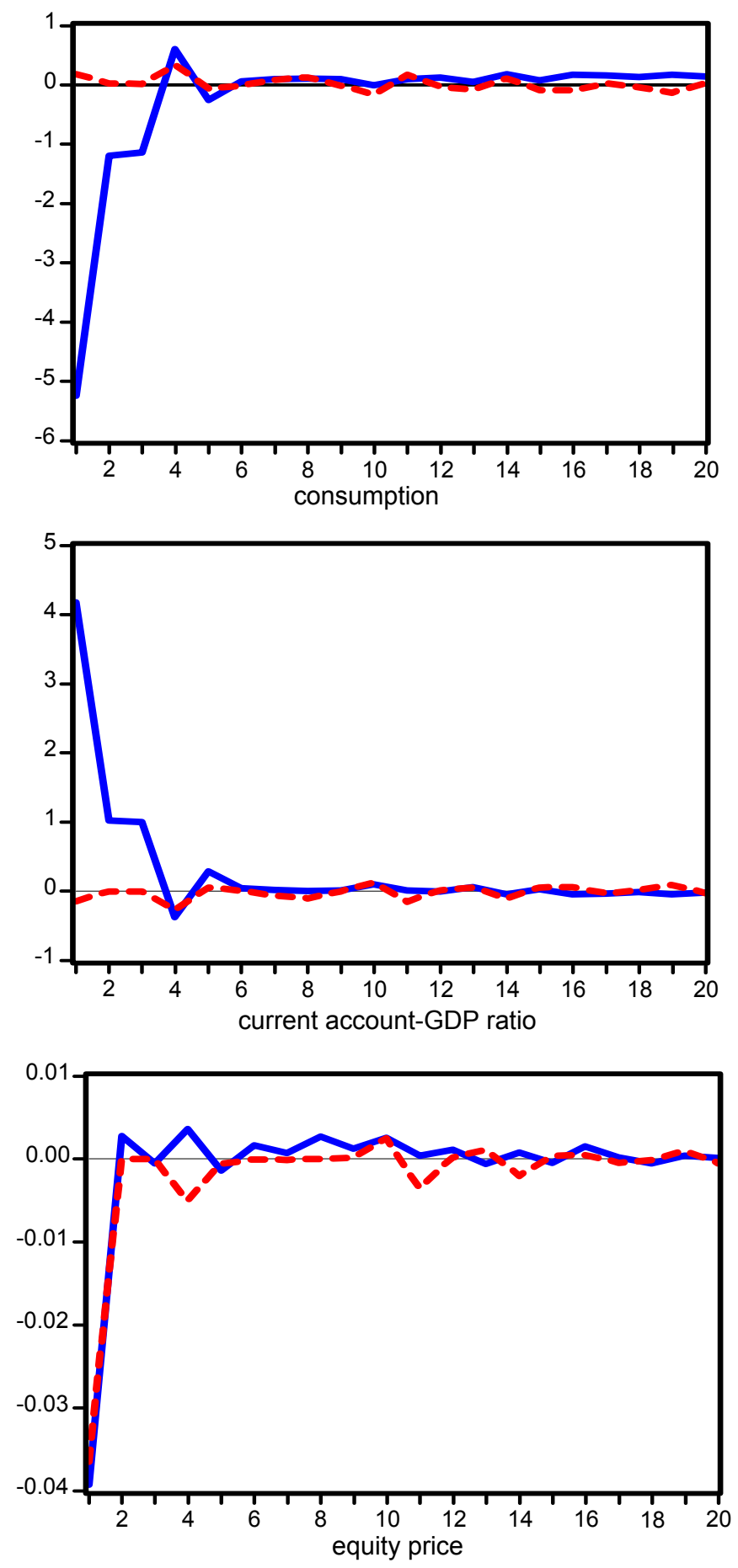

high leverage ratio $(-10.9 \%) \quad-$ low leverage ratio $(-7.4 \%)$

Note: Forecasting functions are conditional on initial states alpha=0.806, $b=-1.01$ and a negative, one-standard-deviation productivity shock. 
Figure 7. Sudden Stop Dynamics in Economies with Low Foreign Asset Demand Elasticity (differences in forecasting functions in response to productivity shock in high leverage states)
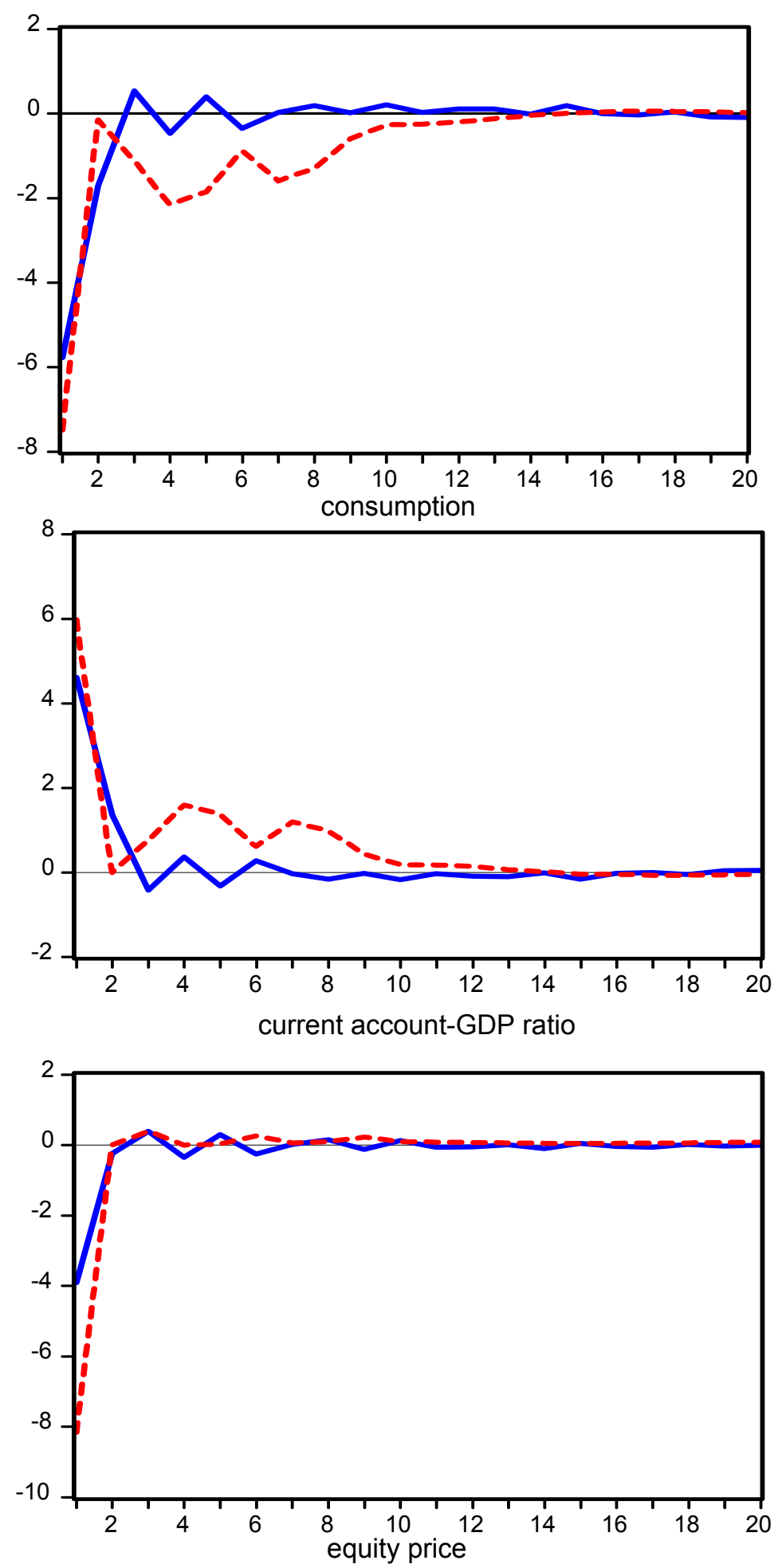

unitary elasticity $(a=1)$

Note: Recurrent cost set to 0.001 . Forecasting functions are conditional on a negative, one-standard-deviation productivity shock at date 1 , and on high leverage states for equity and bonds. High leverage ratios are $-11.4 \%$ for $a=1$ (with alpha $=0.809$ and $b=-1.46$ ) and $-12.2 \%$ for $a=2$ alpha $=0.815$ and $b=-1.48$ ). 
Figure 8. Asset Trading Costs in Percent of Expected Returns in the Low Productivity State of the Economy with Low Foreign Demand Elasticity

$$
(a=2,1 / a=0.5)
$$

trading costs in percent of equity return

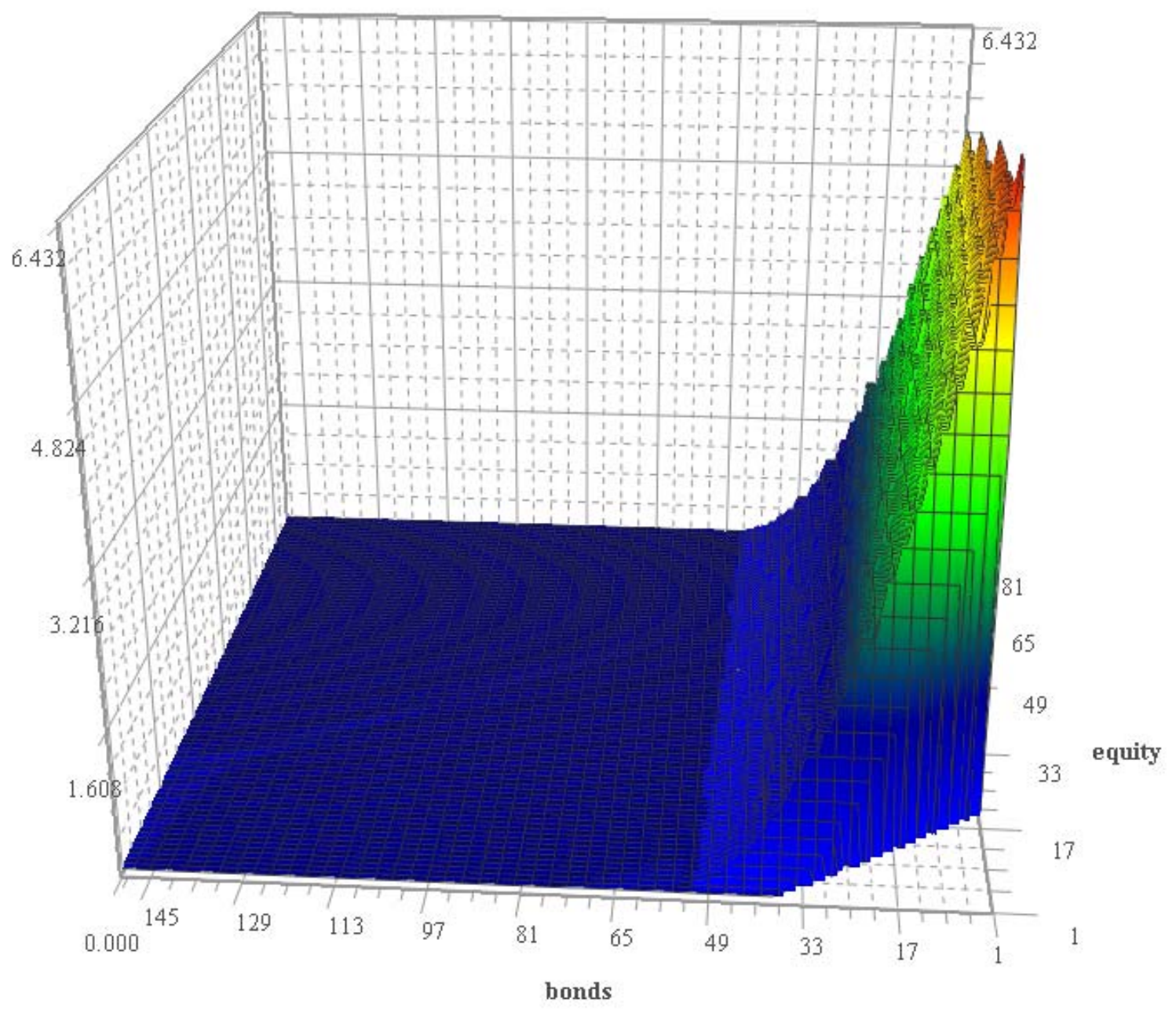

